Document downloaded from:

http://hdl.handle.net/10251/145407

This paper must be cited as:

Buitrago, M.; Sagaseta, J.; Adam, JM. (01-0). Avoiding failures during building construction using structural fuses as load limiters on temporary shoring structures. Engineering Structures. 204:1-16. https://doi.org/10.1016/j.engstruct.2019.109906

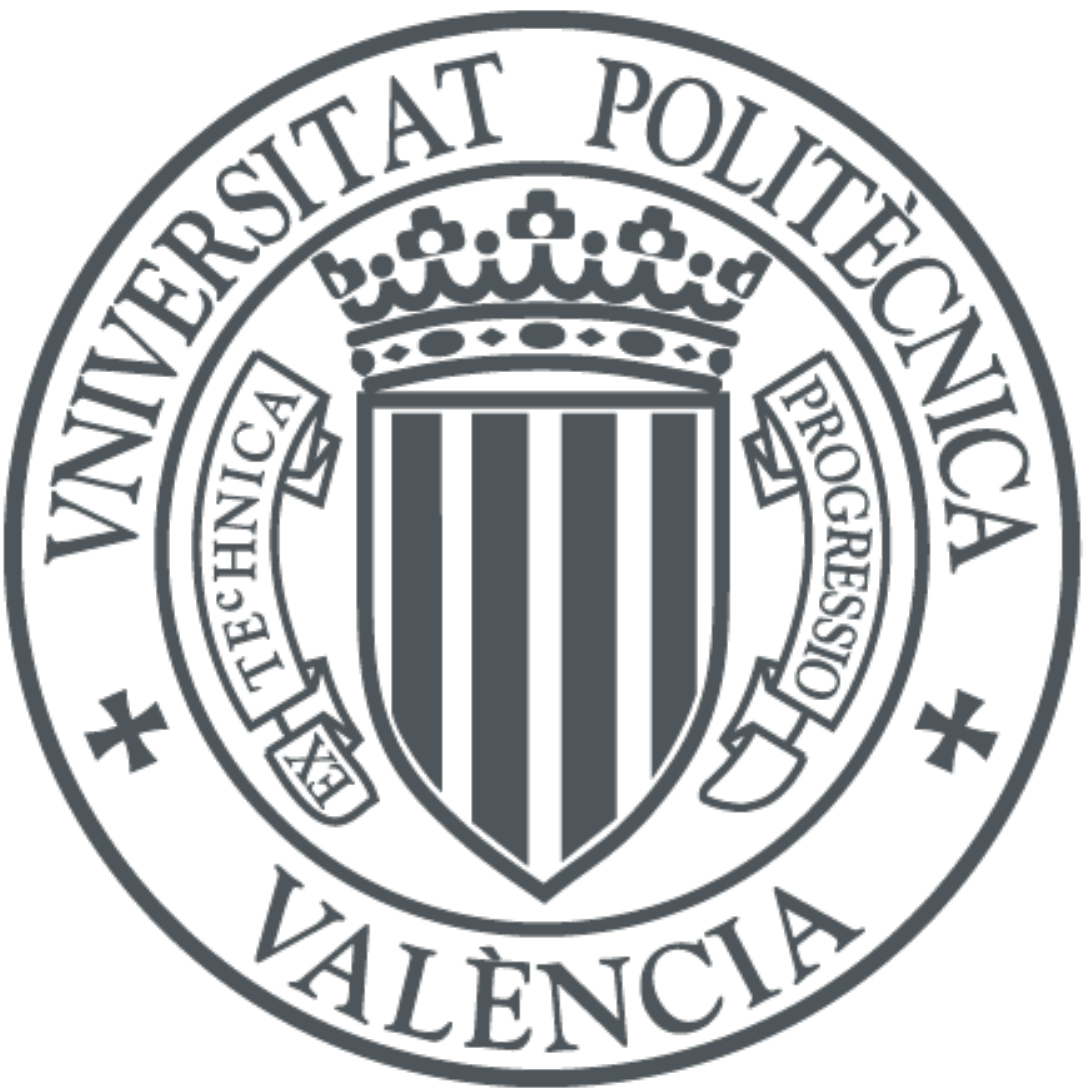

The final publication is available at

https://doi.org/10.1016/j.engstruct.2019.109906

Copyright Elsevier

Additional Information 


\title{
$1 \quad$ Avoiding failures during building construction using structural fuses as load limiters on temporary shoring structures
}

3

\author{
Manuel Buitrago ${ }^{\mathrm{a}}$, Juan Sagaseta ${ }^{\mathrm{b}}$, Jose M. Adam ${ }^{\mathrm{a}}$
}

aICITECH, Universitat Politècnica de València. Camino de Vera s/n, 46022 Valencia, Spain

${ }^{b}$ Department of Civil and Environmental Engineering, University of Surrey, GU2 7XH Guildford, UK

* Corresponding author. Tel.: +44 1483 686649; fax: +44 1483682135 .

E-mail address: j.sagaseta@ surrey.ac.uk (J. Sagaseta).

\section{Abstract}

The risk of structural failure of buildings can be significant during construction. Temporary adjustable telescopic steel shores or props are commonly used in building construction. The failure of shores is sudden and therefore structural fuses as load limiters (LL) can be introduced to provide ductility in the temporary member for a specified limit failure load. Previous work by the authors showed that the design of shoring systems can be improved using LL for standard cases of imposed loads applied during construction. This paper extends this work to cases of accidental loading where the shoring system-permanent structure interaction is less known. The main principles of LLs are discussed and implemented in advanced numerical simulations of a real case RC building during construction by means of explicit nonlinear dynamic finite element analyses. Different local failure scenarios were investigated corresponding to cases observed in practice. The comparison of the numerical results obtained with and without LLs demonstrated for the first time the benefits of using LLs in terms of: a) mitigating the risk of failure of the temporary structure; and b) reducing permanent damage (cracking and short-term deflections in the slab) affecting the durability and functionality of the building.

Keywords: Building; Damage; Load limiter; Progressive collapse; Slab; Steel Shore; Structural fuses. 


\section{Introduction}

Construction is one of the most critical phases in the life cycle of buildings [1-8] due to the risk of failure and the possibility of underestimating construction loads as shown in [9]. Recent review of failure reports from CROSS in 2018 [10], based on over 600 reports mainly from the UK, indicated that in $38 \%$ of the failures reported the cause was related to the construction stage, $36 \%$ to the pre-construction stage due to design, $25 \%$ during normal use and $1 \%$ during demolition. Analysing the causes of specific structural failures and proposing measures to mitigate their effects is an effective measure to reduce risks and improve safety of buildings.

A critical stage during construction is the procurement of the shoring (propping) system including the design, assembly and striking of shores. Codes of practice and guidelines on temporary works have historically focused on key aspects such as communication between the designer, supplier and Temporary Works Coordinator TWC [11], stability and overall design philosophy where members are designed for high loads for short periods of time. Considerations on progressive collapse of temporary shoring are currently being considered in guidelines for design of temporary works (e.g. [12]) with the idea of avoiding local failures that could have severe consequences. This focus follows the international concern on structural robustness [12] and the latest developments in this area captured by international codes for permanent structures [13-15]. However, some guidelines [16] suggest that formwork systems have normally sufficient built-in rigidity to distribute loads to the shores after accidental events. This was demonstrated by the authors in [17] using advanced simulations also showing that the rigidity and redundancy of the shoring system was able to prevent any dynamic amplification in the structure/shoring system.

This raises the question of whether shores should be designed to resist local failure in accidental events; some guidelines mention that this would be uneconomic [16], the results in [17] support this. However, it is recognised in $[16,17]$ that the progressive collapse of the shoring system can occur and the permanent structure might deform excessively in accidental cases leading to cracking and permanent deflections which can affect the service life of the structure. 
52 The main cause of temporary and permanent structural failure during construction (including 53 progressive collapse) is the failure of the shoring system due to excessive loads on shores [9].

In order to mitigate the risk of failure or partial damage of the shoring/structure system during construction this paper investigates the use of structural fuses as load limiters (LLs) to be installed on temporary shoring systems acting as structural fuses and changing the mode of failure of the shore; patented solutions exist to LLs for example ES2636833 [18]. The main idea behind the LLs is that the working load in the shores is kept below and allowable load (See Section 3 for more details). This paper shows novel work investigating the ability of LLs to arrest the propagation of failure of the shoring system under accidental events and mitigate the potential damage on the shore/structure system.

This work focuses on the construction of RC buildings by shoring of successive floors [1925], including a shore clearing process (SCS: Shoring/Clearing/Striking). The SCS approach was adopted in this work as the shoring loads are larger than those using other construction methods without intermediate operations (e.g. SS: Shoring/Striking), or with reshoring (e.g. SRS: Shoring/Reshoring/Striking) [19]. Section 2 of the paper contains a discussion on failures during construction highlighting trends and severity of consequences which are addressed in subsequent sections. Section 3 discusses the role of LLs in accidental events and how they could be implemented in the numerical analyses. Section 4 gives details of the numerical analysis of a real case RC building (shore/structure) including the predicted propagation of failure in cases with and without LLs installed on shores. The analysis includes also a systematic risk analysis to discuss the raw and mitigated risk using LLs. The main conclusions are drawn in Section 5.

\section{Failures during construction}

Many studies have analysed cases of structural failures looking at their causes and providing recommendations or mitigation measures to avoid their repetition. In many cases these reports are confidential although in some other cases the findings are filtered by international associations to alert practitioners on relevant aspects related to safety. The learning acquired from these studies 
(learning from failures) is at present a very active line of research [26-28]. Studies focusing on accidents during construction include $[9,29,30]$.

In many of these reported accidents the failure occurred in the shoring system. An example is shown in Fig. 1, in which many of the shores buckled due to overloading. Shore buckling, together with pin deformation or breakage, are the most frequent mode of failure observed [31]. It is also observed that other shores in Fig. 1 that appear to be undamaged did not carry any load after the incident. In the case shown the permanent structure did not collapse, however other cases have been reported in [9] where such incident have led to the progressive collapse of the entire structure. The concept of progressive collapse is understood as the process by which local damage sets in motion a chain of failures, leading to the collapse of the entire structure or a large part of it [32].
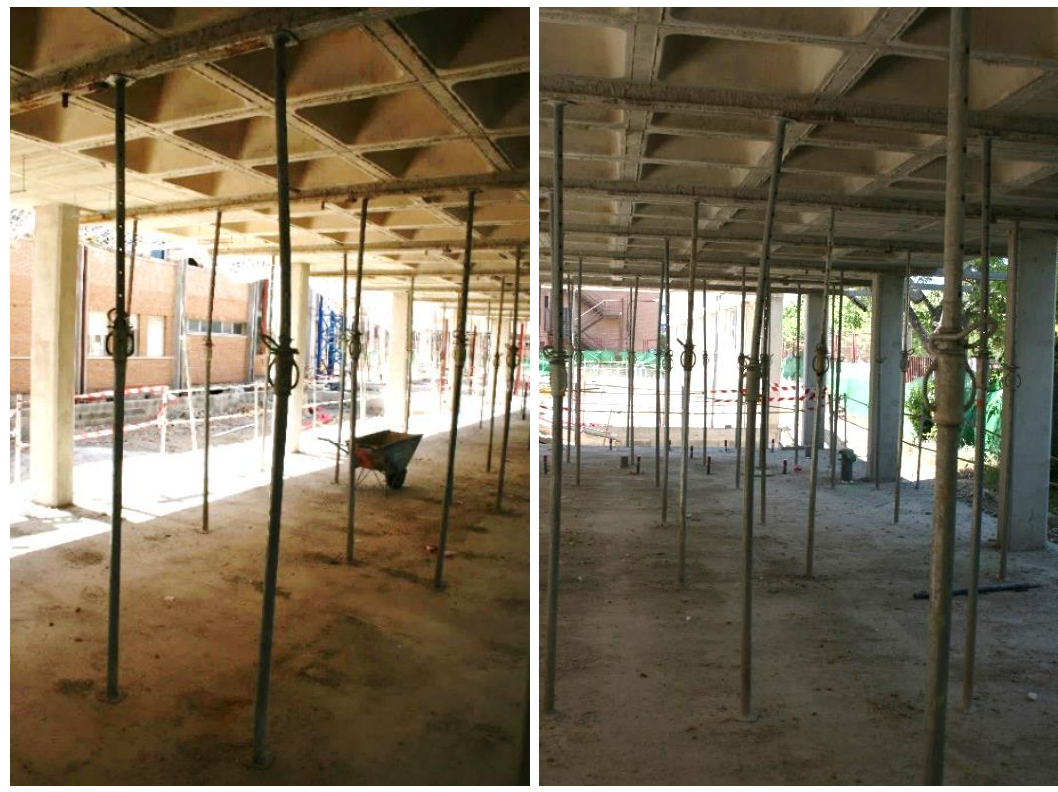

Fig. 1. Shore buckling during the construction of a building structure.

A potential issue in cases as the one in Fig. 1 in which the integrity of the permanent structure was not affected is the consequences during the service life of the building. A serious concern in many of these cases is that the initial damage might not be detected and the structure will be put into service without any repair being considered. This scenario is plausible in cases where there is a lack of supervision. For example, an investigation in the UK commissioned by the HSE [33], which included site investigations and interviews with those involved in procurement, highlighted 
a concerning lack of adequate checking and erection accuracy. Allowing elements with early-age concrete to crack due to overloading during construction, as often happens, may cause excessive

100 instant and long-term deflections and reduced strength of the structure. An example is given by

101 Whittle [34] where a flat slab in a hotel built in the 1970s had excessive deflections due to sagging of the formwork and early striking; during some refurbishment works 20 year after it was built, it was found that the structure was unsafe and costly remedial work were needed. The work presented in this paper is aimed at avoiding such accidental situations by introducing LLs; the fundamentals of LLs are described in detailed in the following section.

\section{Load limiters on shores: description and simulation}

The concept of a load limiter on shores was conceived with the aim of avoiding failures during construction and reducing the risk of collapse $[35,36]$. The main idea behind the LLs is that the working load in the shores is kept below an allowable load. In accidental situations studied in this

111 paper this means that the most heavily shores reach a constant load (limit load) and the excess

112 load needed to withstand the event is redistributed to neighbouring shores acting as a group. In

113 this way, sudden failures of the shoring system, which can often lead to severe consequences, are

114 avoided or mitigated as demonstrated in subsequent sections.

115 Fig. 2 shows a shoring scheme commonly used in practice consisting of shores, joists and

116 formwork boards as well as an example of a particular device [36] acting as LL assembled in an

117 adjustable telescopic steel shore. The type of shore considered in this work is formed by inner and

118 outer telescopic tubes, a fine-adjustment thread for altering shore height, and a ring to transmit

119 the load from pin to thread. The LL shown in Fig. 2, as a particular development of LLs, is formed

120 by a pair of connected elements installed between the shore pin and ring that interrupt and control

121 the transmission of the shore load. The technical and economic viability of LLs was demonstrated

122 in Buitrago et al. [35], who also showed its capacity for improving construction safety, temporary

123 shoring system costs and structural efficiency for normal construction loads. 


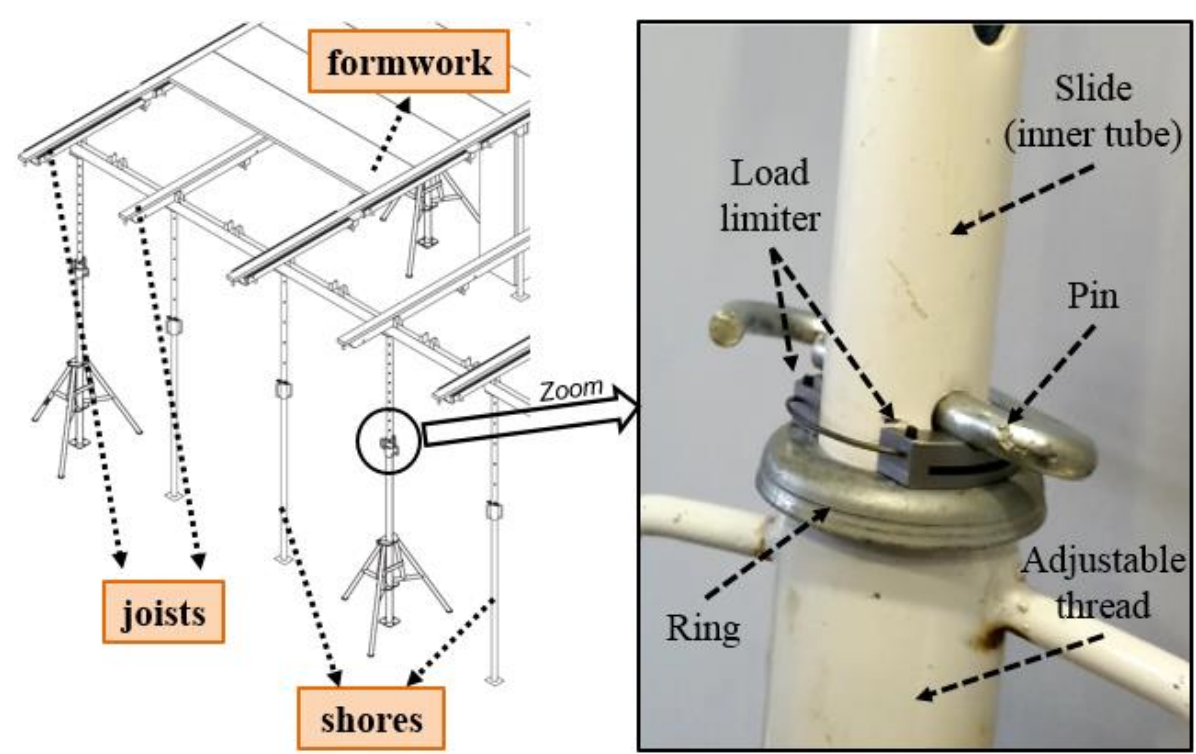

Fig. 2. Sketch of the shoring system and detail of a shore with load limiter.

The LLs investigated in this work were designed to initiate plastic behaviour at a certain limit load and allow a controlled vertical displacement $(\delta)$ of the shore with the excess load. During the controlled descent the shore remains operative avoiding the overload and the possible failure of the shore. The start of plastic behaviour involves the formation of three plastic hinges on the upper part of the LL device. Fig. 3 shows the LL behaviour before and after reaching the limit load by means of a simplified structural model. For safety and functionality reasons, plastic deformation in the LLs is limited to a maximum value, in this case this is equal to the height of the LL slot (see Figs. 2 and 3). Once the maximum plastic deformation is reached the shore is reactivated (i.e. is able to carry increasing load until it fails) following a linear elastic behaviour similarly as for loads below the limit load. Fig. 4 a gives an example where the LL has reached the maximum permitted plastic displacement (i.e. contact starts between the top and bottom of the slot). 


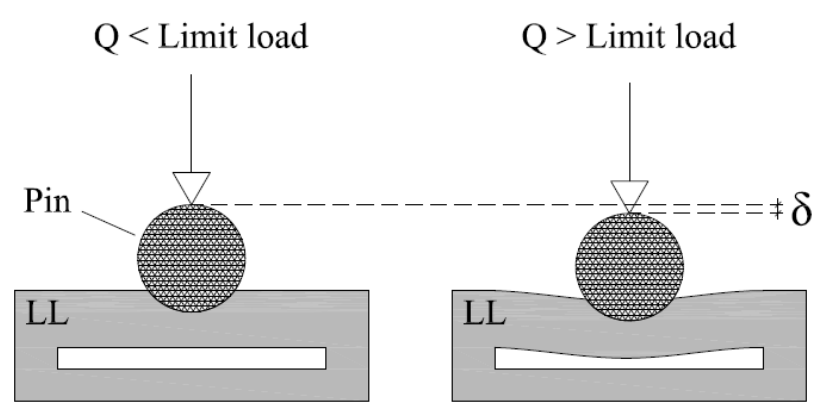

Simplified model for the upper part of LL
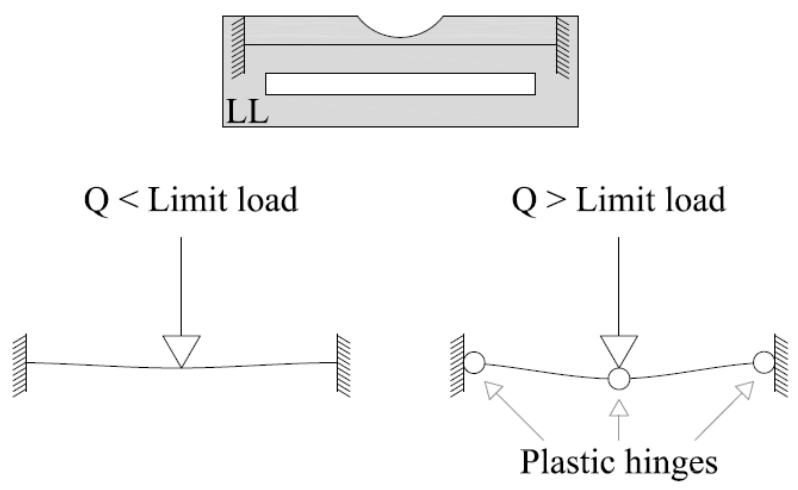

Fig. 3. LL conceptual behaviour before and after reaching the limit load.

(a) (b)
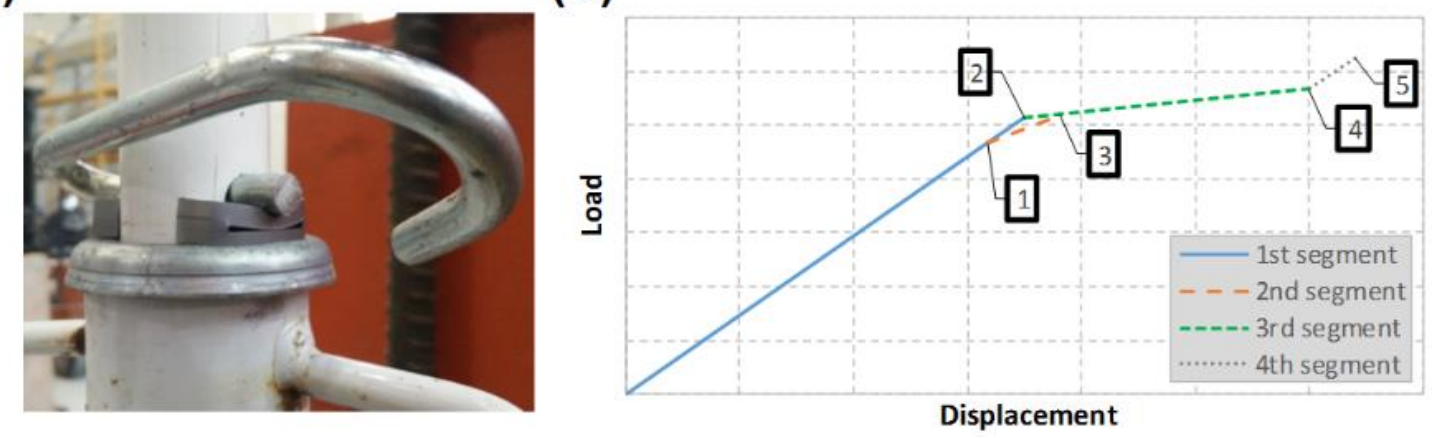

Fig. 4. a) Load limiter after reaching the maximum plastic displacement (slot height), and b) simplified LL on shore behaviour adopted for macro-scale models.

The response of LL devices can be implemented in structural analysis models. Fig. 4b shows the simplified qualitative and parameterised load-displacement behaviour of the shore-LL system. This simplified behaviour was adjusted empirically based on an extensive test campaign [36]. The model can be used for macro-scale numerical simulations. The different segments of the simplified load-displacement curve are defined systematically as follows:

- Point 2: Defines the limit load of the LL $\left(q_{y}\right)$. The first segment has a slope (stiffness) of $E^{\prime} A / L$ considering a small reduction of the elasticity modulus $\left(E^{\prime}\right)$ from $210 \mathrm{GPa}$ 
to 190GPa in order to include the LL effect, and the area and length of the shore ( $A$ and $L$ respectively).

- Point 4: Defined as the maximum plastic displacement in the LL. The third segment has a slope equal to $15 \%$ of the initial slope $\left(0.15 \cdot E^{\prime} A / L\right)$.

- Point 1: Determined by a load equal to the limit load $\left(q_{y}\right)$ reduced by $1.1\left(q_{y} / 1.1\right)$.

- Point 3: Intersection of the second and third segments. The second segment has a slope equal to $57.5 \%$ of the initial slope $\left(0.575 \cdot E^{\prime} A / L\right)$. initial slope.

The load-displacement curve described above was adopted in the advanced numerical simulations in subsequent sections (path 1-3-4-5). These analyses were carried out to assess the

160 propagation of failure of the shoring system after different accidental scenarios. The following 161 aspects were considered in the analysis: non-linear behaviour, sudden removal of critical shoring members, contact modelling between structure and shoring system and realistic modelling of the

163 LLs. It is worth noting that alternative LLs to the one investigated herein are expected to lead to 164 similar conclusions assuming that the LLs share similar principles to those described in this 165 section.

\section{Failure and damage mitigation using structural fuses as load limiters on shores}

168 This section contains a comparison of the results from structural analyses of a building during 169 construction with and without LLs subjected to different accidental events. The authors had 170 previously studied the effects of sudden failure of shoring elements in RC building structures under construction without LLs [17]. This previous work focused on scenarios of severe shoring

172 system failure including: a) progressive collapse of shoring or even of the entire shoring system, 173 and b) severe extended damage to the permanent RC structure. This section deals only with the 174 most severe damage scenarios observed in [17]. The following subsections include: a) a 
175 description of the building and the shoring system used in the study, b) a description of the FE

176 model including the LLs, c) failure scenarios considered, and d) discussion of the results.

\section{4.1. Building structure and shoring system considered}

178 A study was carried out on an actual building designed in accordance with Eurocode 2 [15],

179 and described in detail in Concrete Society [37]. The structure consisted of 300mm thick RC flat 180 slabs, $3.5 \mathrm{~m}$ inter-floor height (3 floors) and $40 \times 40 \mathrm{~cm}^{2}$ cross-section irregularly distributed 181 columns (see Fig. 5). A full description of the building, which was previously investigated in 182 other studies, can be found in Buitrago et al. [17] and Olmati et al. [38]. Fig. 5 contains a 3-D 183 view of the building and a plan view of the shoring system of one of the floors.

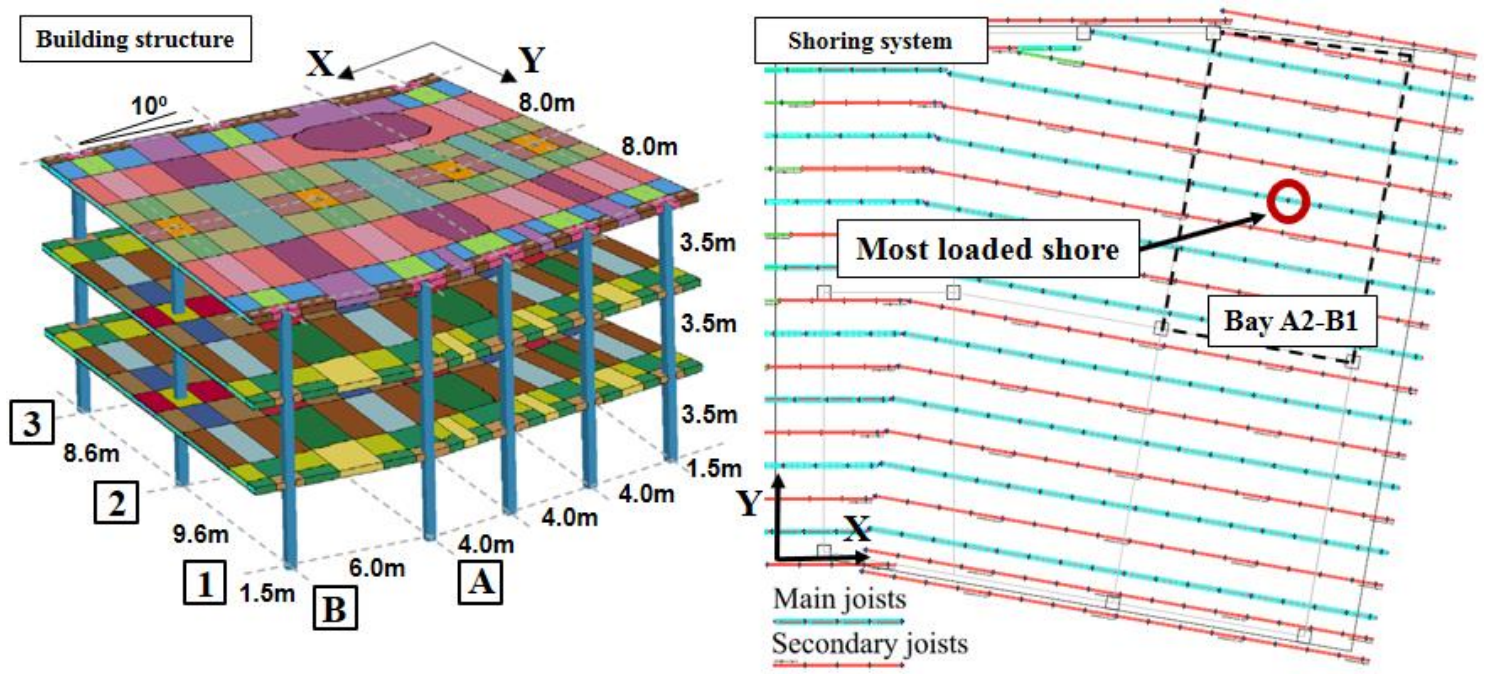

Fig. 5. Building geometry and the shoring system considered.

The temporary steel shoring system adopted in this work was identical to that designed by

187 Buitrago et al. [17] so that a direct comparison could be made with the same case but using LLs.

188 The construction process considered was also similar, including a clearing of $50 \%$ of the shores 189 belonging to the secondary joists in Fig. 5 (see also Fig. 6a), with three consecutively shored 190 floors (2 cleared and one totally shored). Joists and shores were separated by a distance of $1 \mathrm{~m}$ 191 and the inter-joist distance was $2 \mathrm{~m}$ after clearing; a new floor was poured every 7 days. The 192 construction method adopted in the analysis was Shoring/Clearing/Striking (SCS) [19] as it was 193 thought to be more critical compared to other approaches (i.e. the shores are more heavily loaded). 194 In this construction process each floor has three operations: i) installing all shores or props for the 
concreting (shoring), ii) after few days removing only the 50\% of props and all the formwork

196 (clearing - removed props were those under the secondary joists as represented in Fig. 5), and iii)

197 removal of the complete temporary structure of the floor as the final step (striking).

198 The selected shore [39] had a maximum strength of $47.7 \mathrm{kN}$ (slightly higher than the expected 199 maximum load of $47.6 \mathrm{kN}$ ) following the design approach described in [17] considering the 200 different construction stages. The most heavily loaded shore was on the ground floor after pouring 201 the third slab when the concrete was 14 days (compressive strength of $34.3 \mathrm{MPa}$ ) and 7 days 202 (compressive strength of 29.6MPa) old on the first and second floor respectively. Fig. 5 shows 203 the position of the most heavily loaded shore placed in bay A2-B1. The maximum loads on shores 204 are usually found on the ground floor (in contact with the foundations) at the time of placing the concrete at the highest floor [24]. Different scenarios were modelled for this most unfavourable position in the shoring system and compared with the same model with LLs installed on the shores; the results are discussed in Sections 4.2, 4.3 and 4.4.

\section{4.2. Description of the FE model}

209 The FE model adopted for the building is shown in Fig. 5 and Fig. 6a with two cleared levels

210 and one totally shored. The model of the permanent structure had been previously verified against

211 a similar FE model reported in [37]. The numerical simulations were performed using LS-DYNA

212 [40], with a structural analysis in the time domain by means of an explicit algorithm and 213 considering the material and geometric non-linearities. All the shores had compatibility of 214 displacements and free rotation (as hinges) in the upper and lower nodes. The lower nodes of the 215 shores on the ground floor also had restricted displacements. Joist-slab, joist-formwork boards 216 and formwork board-slab connections were modelled as contacts. Shell elements were used for 217 slabs and formwork boards, while beam elements were used for columns, shores and joists. 218 Further details on the FE models of both the permanent RC structure and temporary shoring system can be found in Buitrago et al. [17] and Olmati et al. [38]. 


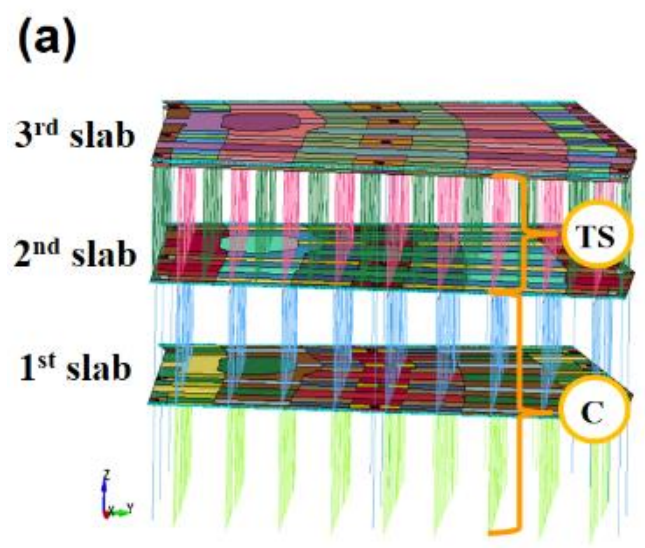

TS: Totally shored floor C: Cleared floor

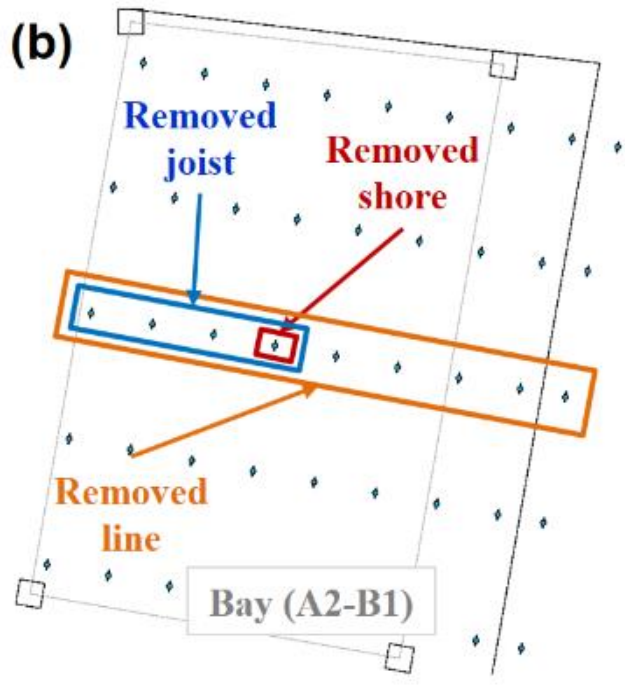

Fig. 6. FE model (a) and defined scenarios of sudden failure of ground floor shores (b).

The steel shores were modelled using Hughes-Liu beam elements with cross section integration and the piecewise linear plasticity model for the material [40]. For the shores without LLs, a linear elastic behaviour was considered up to a brittle failure defined by their strength. This captured the sudden failure of the shore when reaching the maximum load, as observed experimentally in [31]. For the shores with LLs, the material model was adapted to include the

227 load-displacement curve defined in Fig. 4b following Section 3 with specific values according to 228 the different local failure scenarios considered (see Section 4.3 and Fig. 6b). In the third local failure scenario in Section 4.3, with 47.7kN strength shores, the selected LLs had a limit load of $40 \mathrm{kN}$ (Fig. 7a) whereas in the fourth scenario, with $30.6 \mathrm{kN}$ strength shores, the limit load was $25 \mathrm{kN}$ (Fig. 7b). 

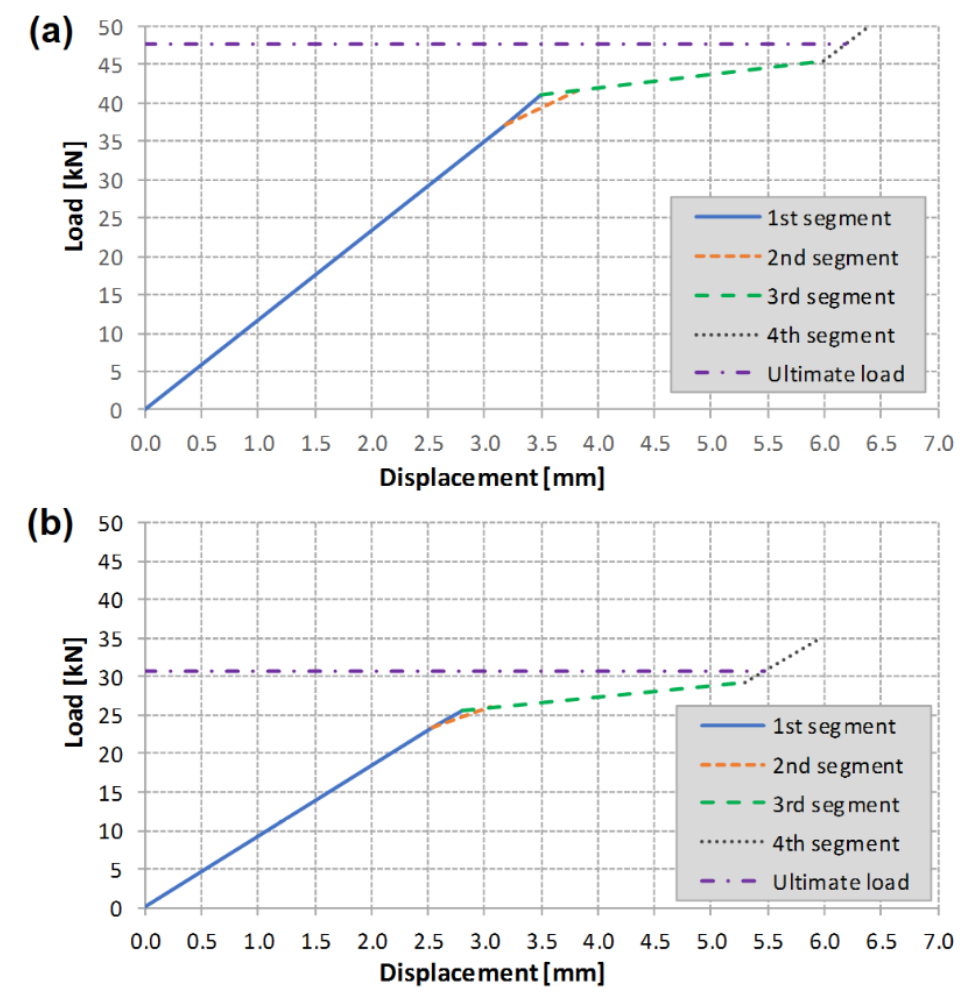

Fig. 7. Load limiter-shore behaviour using: (a) load limiters of $40 \mathrm{kN}$ and shores of $47.7 \mathrm{kN}$ strength for the third failure scenario, and (b) load limiters of $25 \mathrm{kN}$ and shores of $30.6 \mathrm{kN}$ strength for the incorrect selection of shores scenario.

The dead load was applied in the FE model as the self-weight of the different elements 237 (densities of $25 \mathrm{kN} / \mathrm{m}^{3}, 5.3 \mathrm{kN} / \mathrm{m}^{3}$ and $78.5 \mathrm{kN} / \mathrm{m}^{3}$ were adopted for concrete, timber and steel 238 respectively). The live load was applied as a uniformly distributed mass on the slab, with a value 239 of $1.0 \mathrm{kN} / \mathrm{m}^{2}$ representing a load due to personnel only [41]. Self-weight of the shoring system 240 was automatically taken into account in the FE model. The load safety factors corresponding to accidental load combinations were considered using the Eurocode [42] (i.e. 1.0 and 0.5 for permanent and live loads respectively). The gravity acceleration was introduced gradually over

243 time between $t=0.0 \mathrm{~s}$ and $0.8 \mathrm{~s}$, similarly as in Olmati et al. [38] and Buitrago et al. [17]. This was

244 followed by a stabilising-time interval after which different failure scenarios were introduced in

245 the bay investigated (A2-B1).

\subsection{Failure scenarios considered}

In the previous study by Buitrago et al. [17] four local failure scenarios were investigated:

1) failure of the most heavily loaded shore (Fig. 6b). 
2) failure of the shores of the joist placed on the most heavily loaded shore (Fig. 6b).

3) failure of the complete shore line on the most heavily loaded shore (Fig. 6b).

4) incorrect choice of shores during design or construction.

The first three cases consider the sudden removal of shores, using the concept of notional member removal (see Fig. 6b). This approach is commonly used in design against progressive collapse and in international codes for permanent structures [13-15] as well as research [38,4348]. The fourth scenario in [17] adopted shores with a strength $(30.6 \mathrm{kN})$ marginally below the strength of the shores used in the other scenarios, and well below the required strength of $47.6 \mathrm{kN}$.

The four failure scenarios are based on plausible design and construction situations observed in different failures during construction as described in [17].

In this paper, the third and fourth failure scenarios were considered in the analysis since it was shown in [17] that the shoring system in these cases suffered progressive collapse whereas in the first and second scenarios progressive collapse of the shoring system was arrested and only some minor damage was observed in the second case. In none of the scenarios investigated in

263 [17] the integrity of the permanent structure was compromised although for scenarios three and

264 four the local damage in the permanent structure was higher leading to a situation where the structural safety would need to be assessed to determine possible repairs.

\subsection{Results and discussion}

\subsubsection{Sudden removal of a shore line ( $3^{\text {rd }}$ failure scenario)}

Fig. 8 shows a plan view of a sequence $(\Delta t=0.1 \mathrm{~s})$ of the progressive collapse of the shoring system on the ground floor in Scenario 3 (see Fig. 6b), which occurred at $t=1.1 \mathrm{~s}$. The framed shores (highlighted in red) are those that disappeared (collapsed) in the next sequence. It can be seen that withdrawing a complete line of shores causes the progressive failure of other shores.

272 Figs. 9a-b show the structure and its displacements before and after the accidental event 273 respectively, for the case when LLs were used, while Fig. 9c shows the results with LLs. In the latter case the progressive collapse of the shoring system is arrested (Fig. 9c). The results show 
276 redistributed the excess load to the neighbouring shores (also equipped with LLs) as intended.

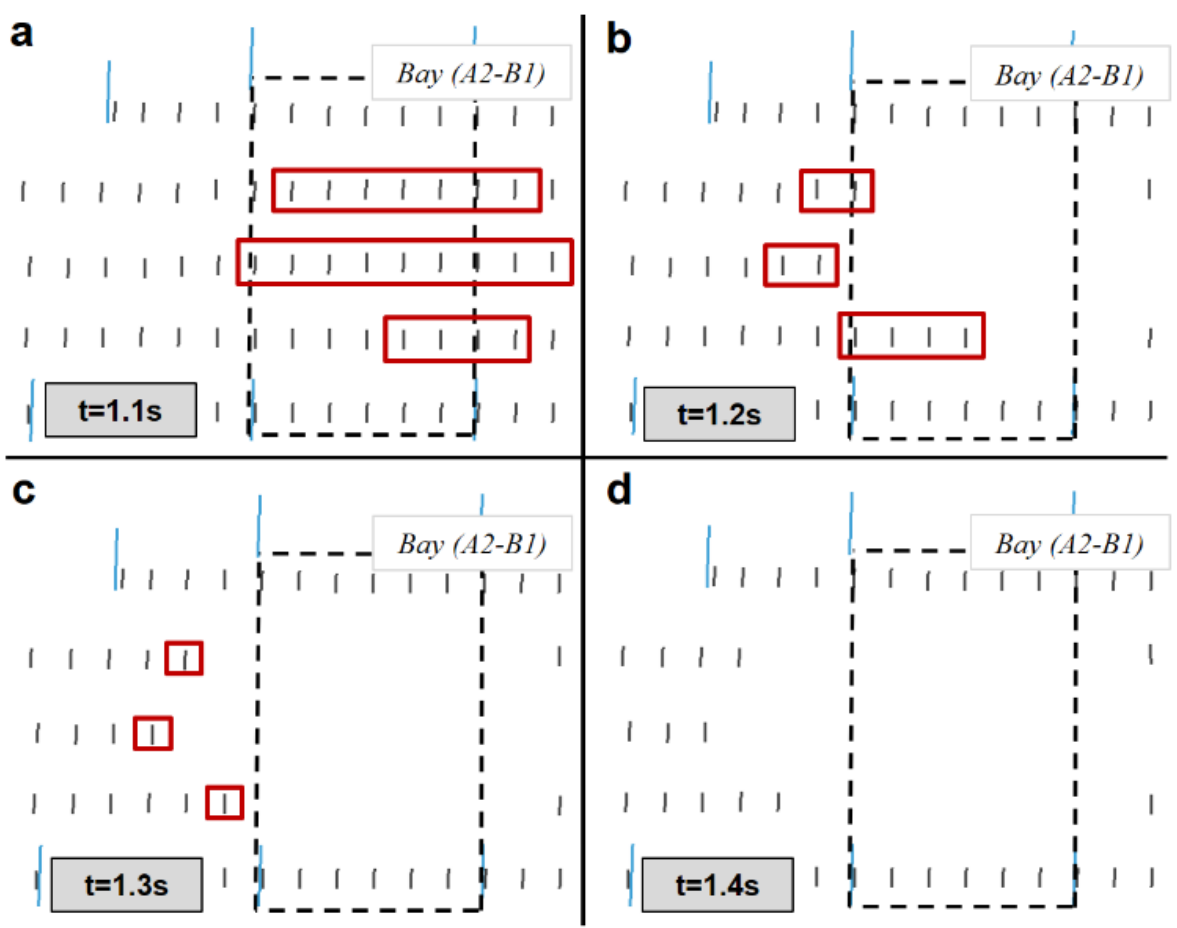

Fig. 8. Progressive collapse of the shoring system in the $3^{\text {rd }}$ failure scenario without LLs.
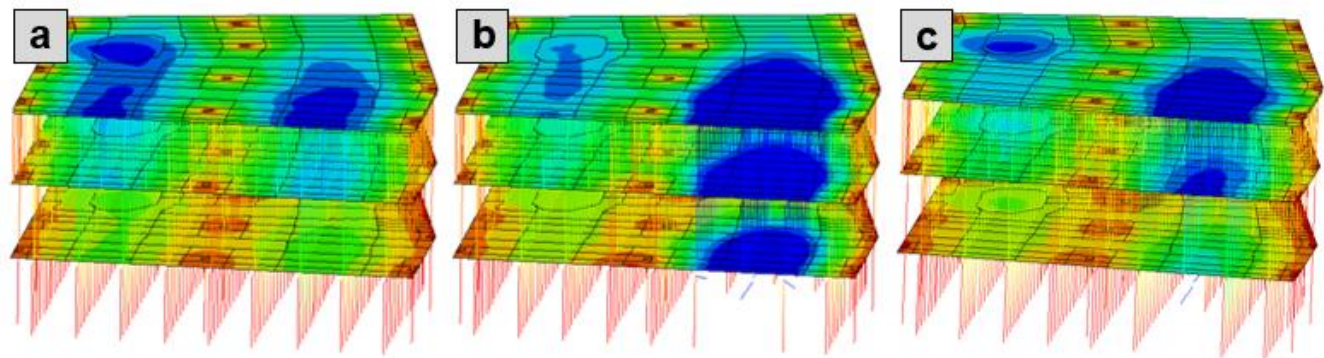

\section{Before accidental event}

\section{Without LL}

\section{With LL}

Displacement

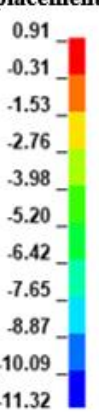

Fig. 9. Displacements and structure/shoring system: (a) before the accidental event, (b and c) after the sudden event, without (b) and with (c) load limiters (LL) on shores (units in $\mathbf{m m}$ ).

Fig. 10 shows the time history results obtained in the slabs and shoring system during application of gravity loads (from $t=0.0 \mathrm{~s}$ to $0.8 \mathrm{~s}$ ), the load stabilisation period (from $t=0.8 \mathrm{~s}$ to $1.1 \mathrm{~s}$ ) and after the sudden failure of a complete line of shores (from $t=1.1 \mathrm{~s}$ to $2.0 \mathrm{~s}$ ), without and with LLs shown on the left and right column graphs respectively.

Figs. 10a-b show, for the cases without and with LLs respectively, the shore loads below the first and second slab corresponding to the $1^{\text {st }}$ and $2^{\text {nd }}$ levels, in the position of the most heavily 
288 loaded shore. After the accidental event at $t=1.1 \mathrm{~s}$, with no LLs on shores, the load on the $2^{\text {nd }}$ 289 level shore reduced significantly (more than 50\%) whereas for the case with LLs this reduction 290 was below $20 \%$. This load reduction observed in both cases was due to the reduced stiffness of 291 the ground floor shoring system after the sudden failure of the line of shores. This reduction was 292 less noticeable using LLs because the progressive collapse of the ground floor shoring system 293 was arrested and a higher number of shores were mobilised after the accidental event.

294 The thicker lines in Fig. 10c show that the progressive collapse in the case without LLs on 295 shores caused a significantly larger displacement for the first $(9.3 \mathrm{~mm}$ increase $)$ and second slab 296 (7.8mm increase) at the position of the most heavily loaded shore under the first slab. However, 297 the use of LLs (Fig. 10d) enabled to arrest the progressive collapse of the shoring system on the 298 ground floor, and therefore the displacements of the slabs were smaller and only due to the sudden 299 removal of the line of shores $(2.5 \mathrm{~mm}$ and $1.4 \mathrm{~mm}$ increase for the first and second slab, 300 respectively). It can also be seen in Figs. 10c-d that the accidental event had no effect on the 301 behaviour of the adjacent bay "AB" (with or without LLs on shores).

302 Figs. 10e-f show, for the case without and with LLs respectively, the loads per unit surface $303\left(\mathrm{kN} / \mathrm{m}^{2}\right)$ carried by the shoring system (S) and slabs (Q) on each floor. For the case without LLs 304 (Fig. 10e), the loads on the shores reduced significantly after the accidental event and as a result 305 the loads on slabs increased significantly. This was not the case when using LLs where the effect 306 of the accidental event on the loads carried on the slabs and shoring systems on each floor was 307 reduced significantly as well as the damage which is further discussed below. 

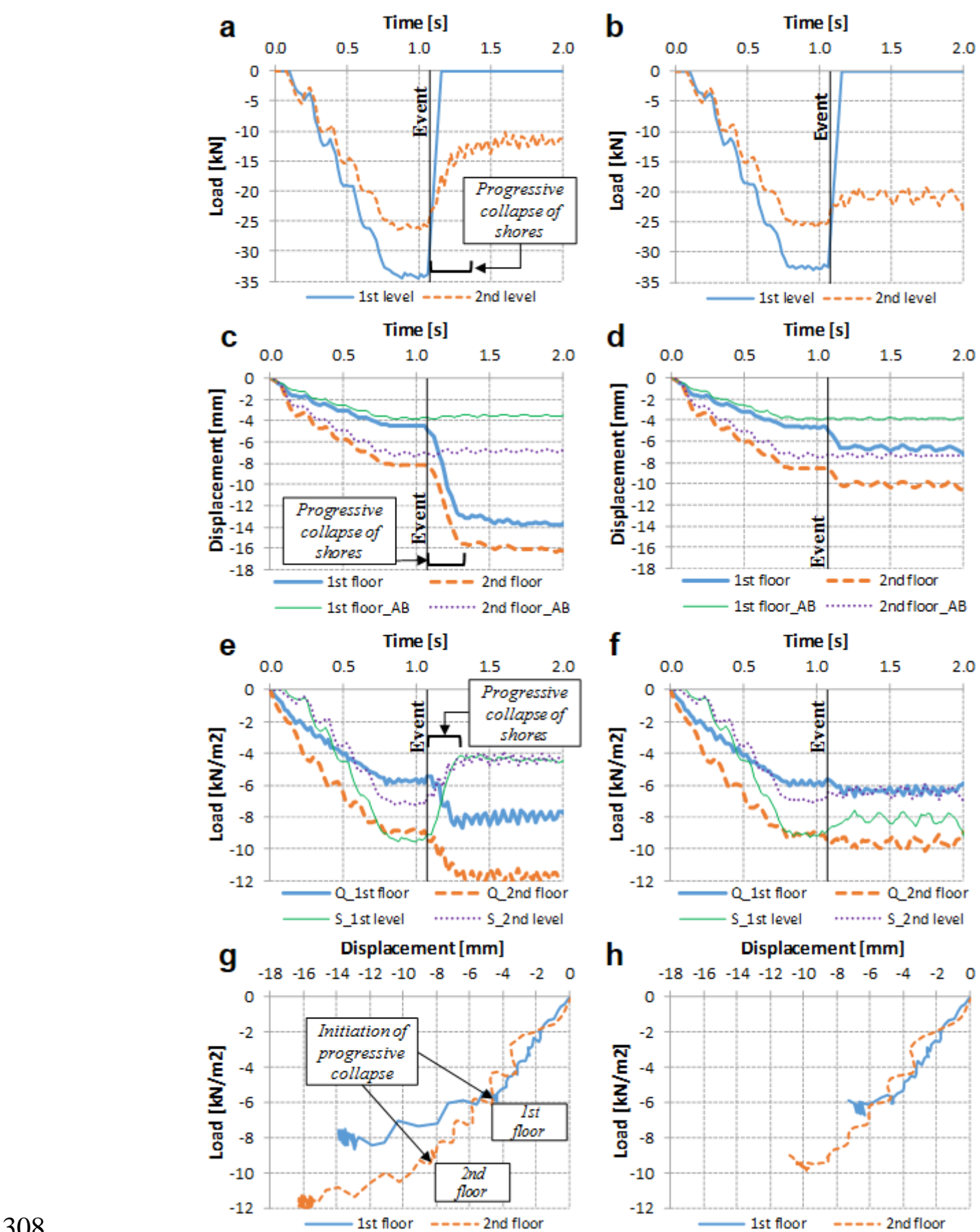

Fig. 10. Time history results of slabs and shoring for the $3^{\text {rd }}$ failure scenario without $L L(a, c, e, g)$ and with $L L(b, d, f, h):$ a) and b) load of a single shore of level 1 and 2 for the most loaded shore under slab 1; c) and d) displacement of first and second floor for the bay under study and the adjacent bay (AB) for the position of the most loaded shore under slab 1; e) and f) slab and shoring system loads for the first and second floor and the $1^{\text {st }}$ and $2^{\text {nd }}$ level respectively; and g) and $h$ ) loaddisplacement of $1^{\text {st }}$ and $2^{\text {nd }}$ slabs (displacement at the position of the most loaded shore of the ground floor).

316 Figs. 10g-h show, for the case without and with LLs respectively, the load-displacement curves of the first and second slabs; the slab displacement corresponds to the position of the most 
318 heavily loaded shore on the ground floor. Without LLs, the slope of these curves (flexural

319 stiffness) reduced significantly when the progressive collapse of the shoring system began. With

320 LLs, excessive cracking was prevented and the slope remained relatively constant (linear

321 behaviour). Fig. 11 shows the reduced cracking due to the LLs. The cracking bending moments

322 in the slab were $51.6 \mathrm{kN}$ and $45.3 \mathrm{kN}$ for the first and second slabs respectively.
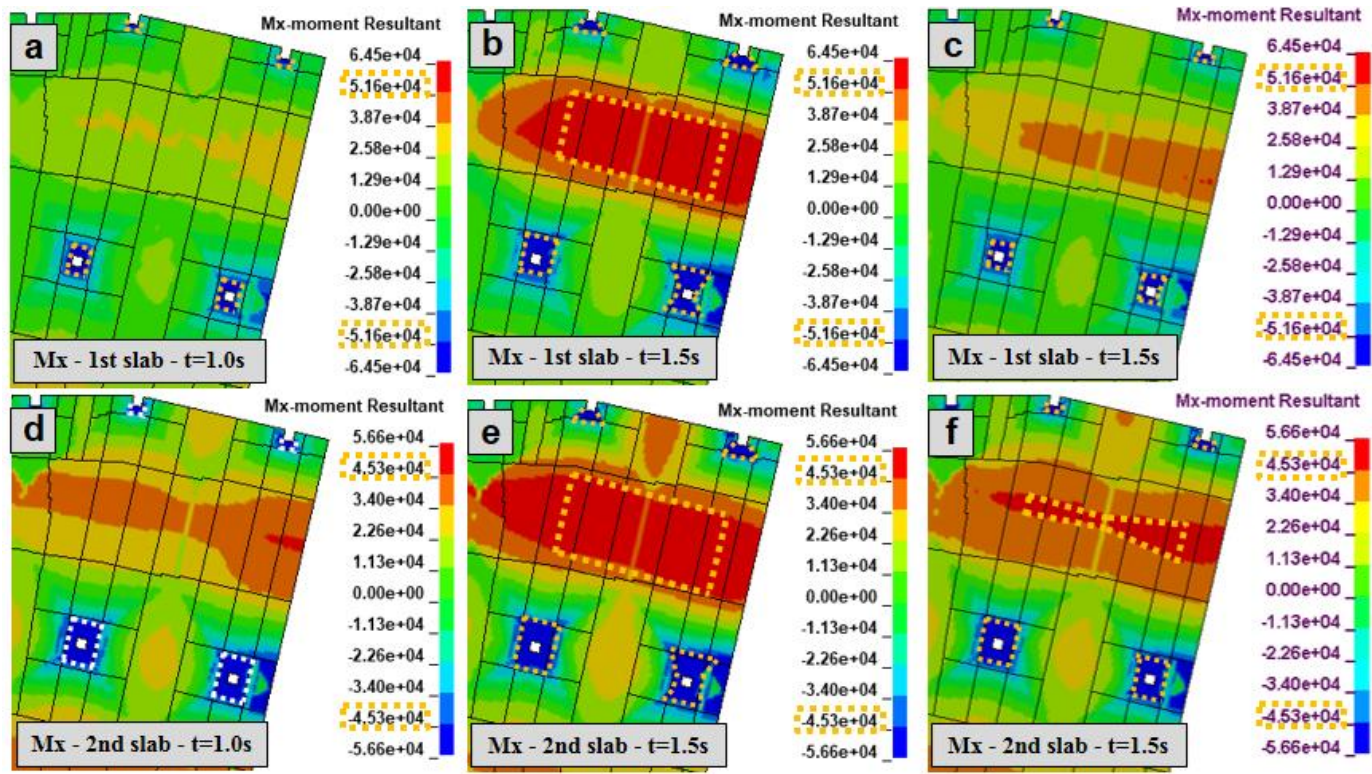

Before accidental event

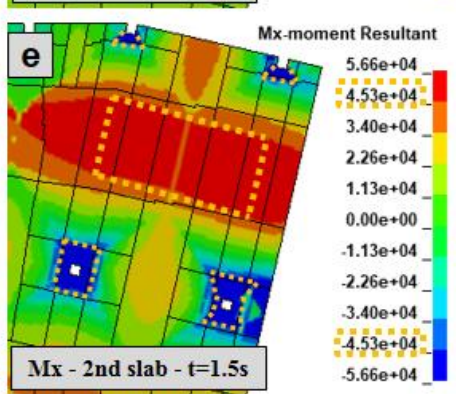

Without LL

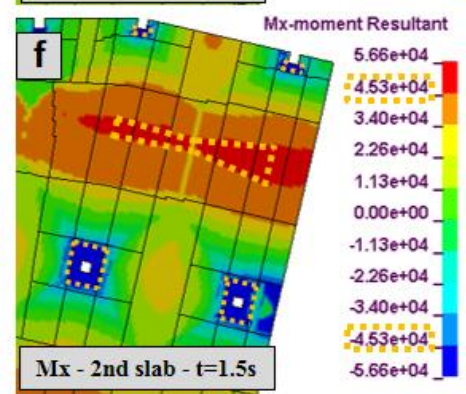

With LL

Fig. 11. Bending moments of first slab (a, b and c) and second slab (d, e and f) before (a and d) and after (b, c, e and f) the accidental event without (b and e) and with (c and f) load limiters (LL) for the $3^{\text {rd }}$ failure scenario (units in $N$ ).

Fig. 12 shows the load on the ground floor shores (plan view) after the sudden removal of the complete line of shores for the case without and with LLs (white -first row- and grey -second row- background boxes respectively). Fig. 12 also gives the percentage of the use of the maximum permitted plastic displacement obtained in the LLs (third row). Without LLs, the only active joists are those at the edges of the bay, with heavy loads on the shores. However, with LLs, all the shores (except those in the failure scenario) remained active and did not reach neither their maximum strength nor maximum permitted plastic displacement. The plastic displacement was only $11 \%$ of the maximum value. LL plastic deformation began in the most heavily loaded shores at points with the highest deformation in the first slab (note that all the edges in bay A2-B1 are continuous except edge A1-B1 which is free). 


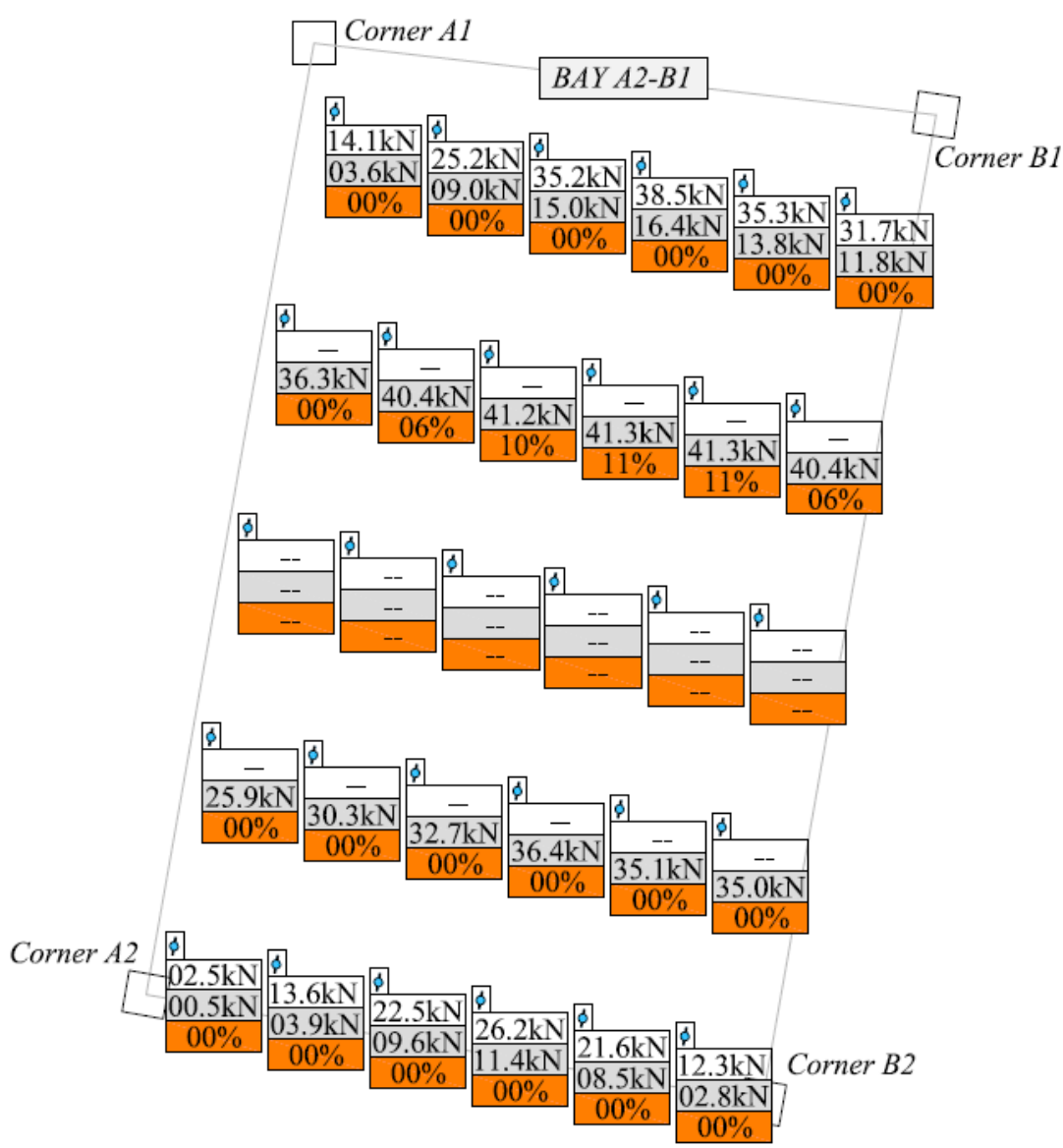

Fig. 12. Ground floor shore loads without LLs (white background-first row-) and with LLs (grey background -second row-), and percentage of use of the maximum plastic displacement of LLS (orange background -third row-).

\section{4.4.2. Incorrect choice of shore ( $4^{\text {th }}$ failure scenario)}

Fig. 13 shows a plan view of the sequence $(\Delta t=0.1 \mathrm{~s})$ of the progressive collapse of the ground

343 floor shoring system in the fourth failure scenario (incorrect selection of shores). For the case

344 without LLs, applying gradually the full gravity load for the placing of the concrete in the third

345 slab (from $t=0.0 \mathrm{~s}$ to $0.8 \mathrm{~s}$ ) triggered the progressive collapse of the ground floor shoring system

346 at $t=0.66 \mathrm{~s}$. The framed shores (highlighted in red) in Fig. 13 are those that disappeared

347 (collapsed) in the following time step. This scenario resulted in the sequential overloading and

348 failure of groups of shores leading to the progressive collapse of the entire shoring system at the

349 ground floor affecting the upper floor levels as shown in Fig. 14a. Fig. 14b shows that the

350 progressive failure of the shoring system did not take place when LLs were fitted to the shores. 


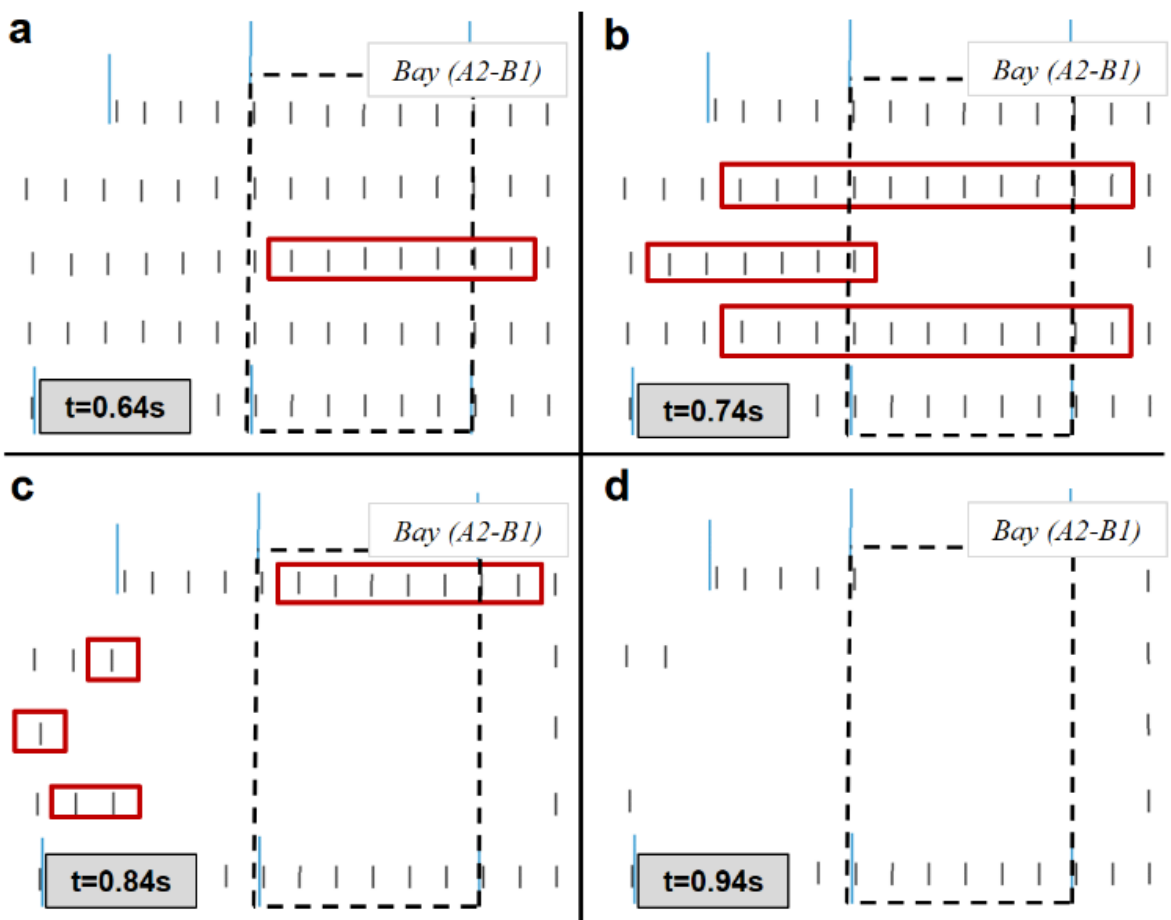

Fig. 13. Progressive collapse of the shoring system in the $4^{\text {th }}$ failure scenario without LLs.
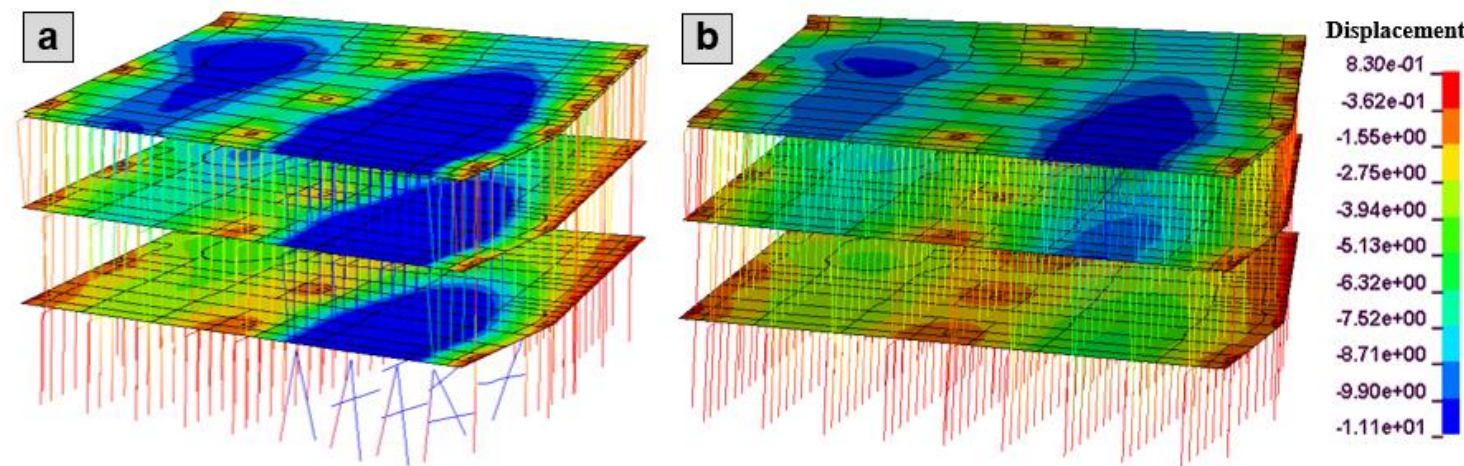

Fig. 14. Displacements and structure/shoring system after the accidental event $(t=1.5 \mathrm{~s})$ for the $4^{\text {th }}$ failure scenario: (a) without LLs and (b) with LLs (units in mm).

Fig. 15 shows the time history results obtained for the slabs and shoring systems during the application of the gravity loads (from $t=0.0 \mathrm{~s}$ to $0.8 \mathrm{~s}$ ) and afterwards (until $t=2.0 \mathrm{~s}$ ); the results are shown for the case without LLs (left column graphs) and with LLs (right column graphs). Figs. 15a-b show, for the case without and with LLs respectively, the shore loads below the first and second slab corresponding to the $1^{\text {st }}$ and $2^{\text {nd }}$ levels at the position of the most heavily loaded shore. Without LLs, the load on the most heavily loaded shore on the ground floor dropped to zero when the shore reached its strength $(30.6 \mathrm{kN})$, whereas with LLs the maximum load reached values slightly over $25 \mathrm{kN}$ (corresponding to LL limit load). In the case where LLs were not used, 
364 the load on the corresponding shore on the second level reduced significantly (Fig. 15a) due to

365 the reduced stiffness of the first shoring level after the accidental event. If LLs were used, the

366 load on the shore on the second level remained constant after the accidental event (Fig. 15b).

367 The thicker line in Fig. 15c shows that progressive collapse without LLs caused a significant 368 increase in the vertical displacement in the first slab (about $15.3 \mathrm{~mm}$ ) and second slab (about $36914.0 \mathrm{~mm}$ ) at the position of the most heavily loaded shore below the first slab. However, with LLs 370 (Fig. 15d) progressive collapse of the ground floor shoring system was avoided and the slab 371 displacements remained constant. In Figs. 15c-d it can also be seen that the failure scenario did 372 not affect the adjacent bay "AB" regardless of whether LLs were used.

373 Figs. 15e-f show, for the case without and with LLs respectively, the loads per unit surface $374\left(\mathrm{kN} / \mathrm{m}^{2}\right)$ carried by the shoring system (S) and slabs (Q) on each floor. In the case without LLs 375 (Fig. 15e), after the accidental event, the loads on the shoring systems at the $1^{\text {st }}$ and $2^{\text {nd }}$ level 376 reduced significantly as the loads on the slabs increased. When LLs were used, the effect of local 377 failure due to choosing the incorrect shores was mitigated completely and the permanent RC 378 structure remained almost undamaged; the level of damage is discussed below.

379 Fig. 15g-h shows the load-displacement curve of the first and second slabs for the case 380 without and with LLs respectively; the displacements were measured at the position of the most 381 heavily loaded shore on the ground floor. When LLs were not used, the slope of the curves 382 reduced significantly after the start of the progressive collapse of the shoring system similarly as 383 in Fig. 10g for the $3^{\text {rd }}$ failure scenario. When LLs were used, the slope of the load-displacement 384 curve was constant (Fig. 15h) which confirmed that cracking in the slab was minimal (linear 385 behaviour of the slab). It can be concluded that the LLs were effective in reducing the damage in 386 the slab after the incorrect shore was selected with strengths well below the required strength. 
a

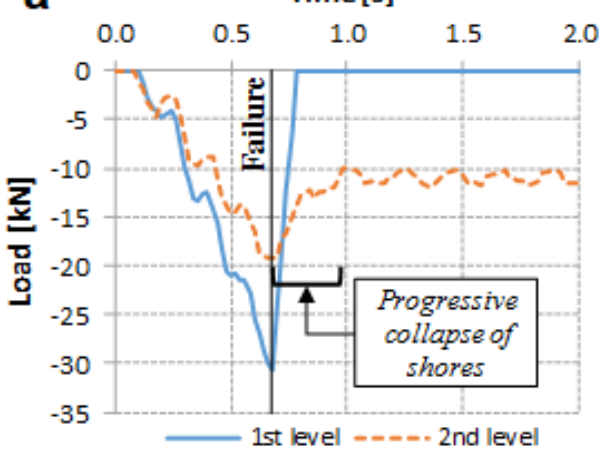

Time $[\mathrm{s}]$
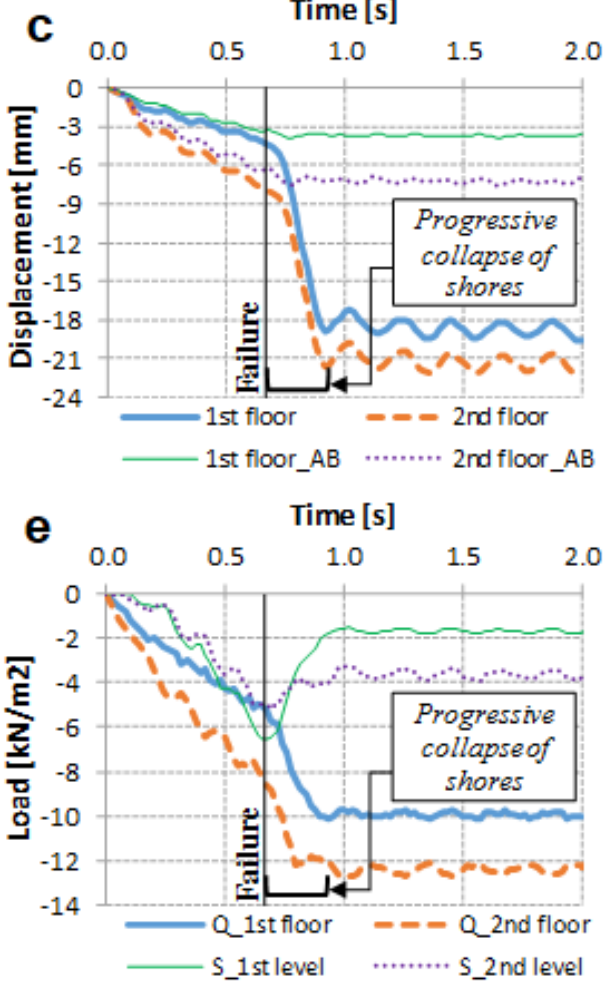

Displacement $[\mathrm{mm}]$

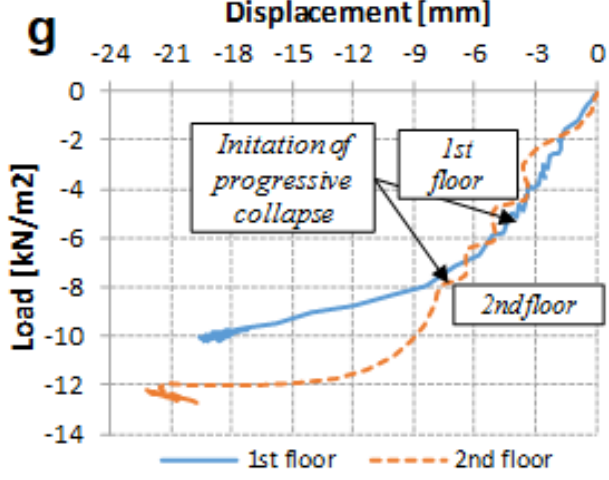

b

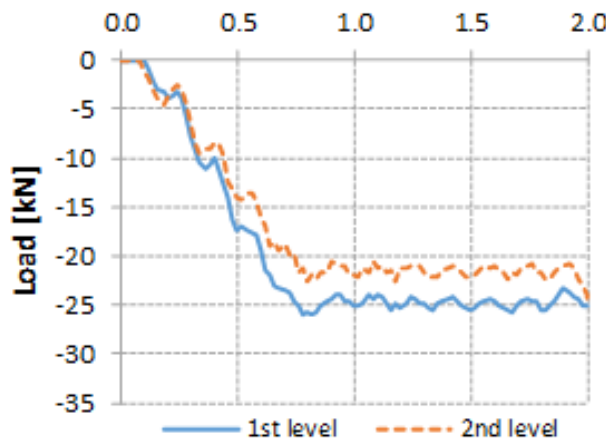

d

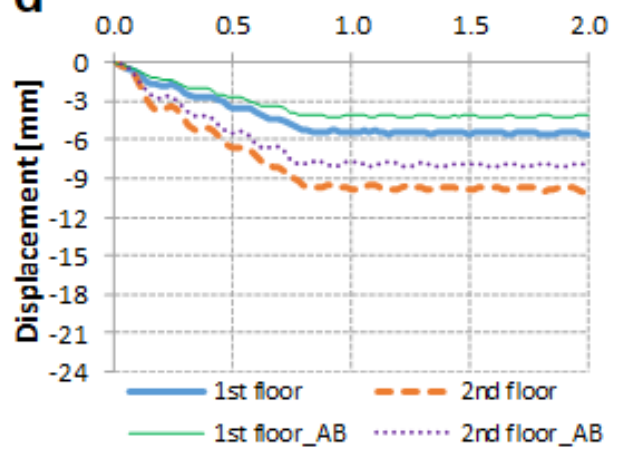

Time [s]

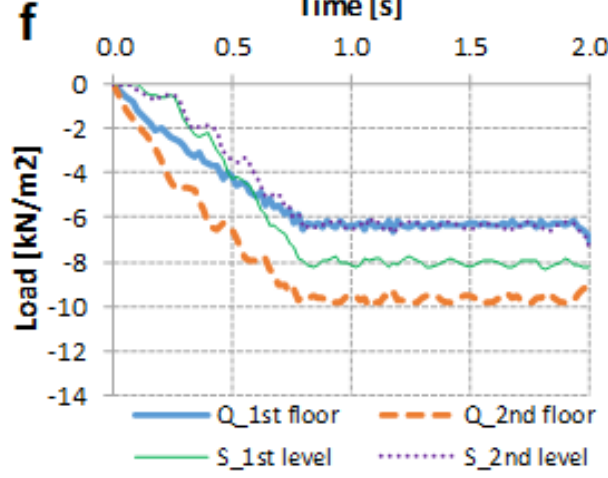

h

Displacement [mm]

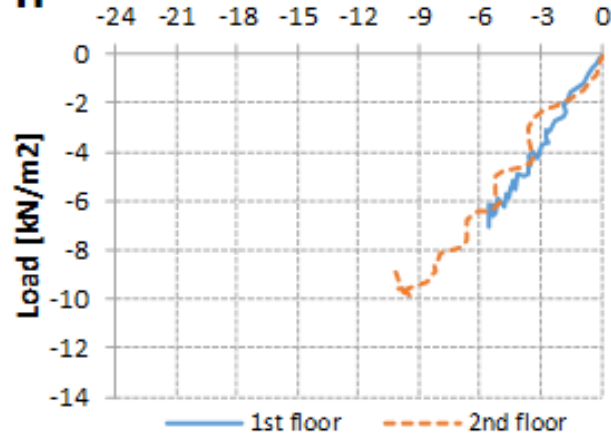

Fig. 15. Time history results of slabs and shoring for the $4^{\text {th }}$ failure scenario without $L L$ (a, c, e, g) and with $L L(b, d, f, h)$ : a) and b) load of a single shore of level 1 and level 2 for the most loaded shore under slab 1 ; c) and d) displacement of first and second floor for the bay under study and the adjacent bay $(\mathrm{AB})$ in the position of the most loaded shore under slab 1; e) and f) slab and shoring system loads for the first and second floor and the $1^{\text {st }}$ and $2^{\text {nd }}$ level respectively; and g) and $h$ ) loaddisplacement of $1^{\text {st }}$ and $2^{\text {nd }}$ slabs (displacement at the position of the most loaded shore of the 
Fig. 16 shows the cracked areas in the slab in the case without LLs (enclosed by broken lines

396 for Bay A2-B1 under study). The cracking bending moments in the slab were $51.6 \mathrm{kN}$ and $45.6 \mathrm{kN}$

397 for first and second slabs respectively. Fig. 17 shows the cracked areas for the case with LLs

398 which is significantly reduced compared to the case without LLs in Fig. 16. These results show

399 the potential of using LLs. Selecting the incorrect type of shore is not uncommon and it can also

400 represent cases of unexpected live loads during construction for which the shores are not designed

401 for. The LLs could act as a simple risk mitigating measure to protect against the effects of

402 uncertainty of construction loading.

403 Fig. 18 shows the loads on the ground floor shores without and with LLs. Similarly, as in Fig.

40412 , the calculated percentage of the use of the maximum permitted LL plastic displacement is

405 shown in Fig. 18. Without LLs, only one of the joists (at the edge of the bay) remained active

406 whereas with LLs all the shores remained active without reaching their maximum strength or their

407 maximum permitted plastic displacement. The shore with the largest plastic displacement reached

408 only $30 \%$ of the maximum allowed. The plastic deformation in the LLs began in the most heavily

409 loaded shores at the centre of the bay in the direction of the points in the slab with the highest

410 deformation. Although many of the shores reached the limit load of the LL, the shores and LLs

411 would be reusable. In order to reuse shores and LLs, a limit of the plastic deformation of $50 \%$ of

412 the maximum plastic deformation is recommended by [36] based on experimental evidence. 

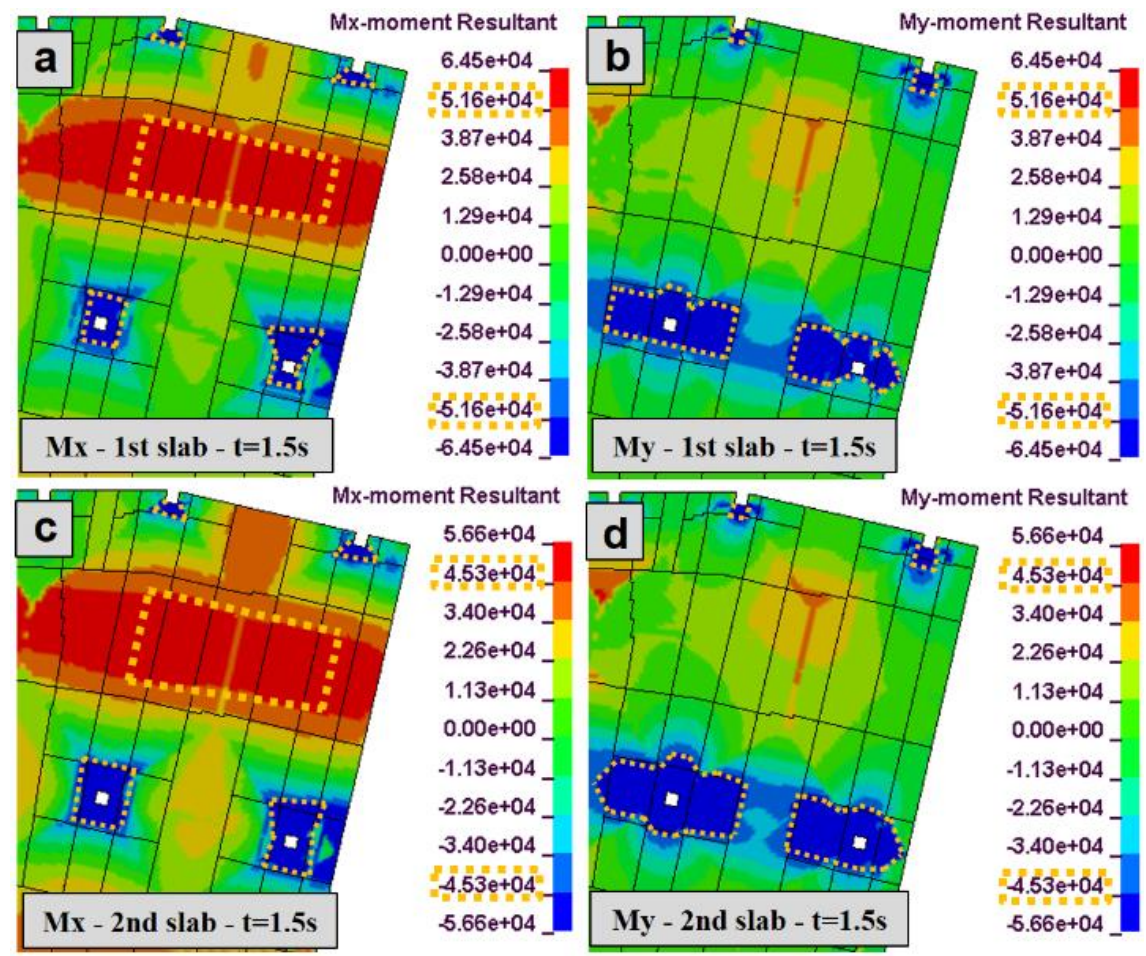

414 Fig. 16. Bending moments of first slab (a and b) and second slab ( $c$ and d) after the accidental event for the $4^{\text {th }}$ failure scenario, without load limiters on shores (units in N).
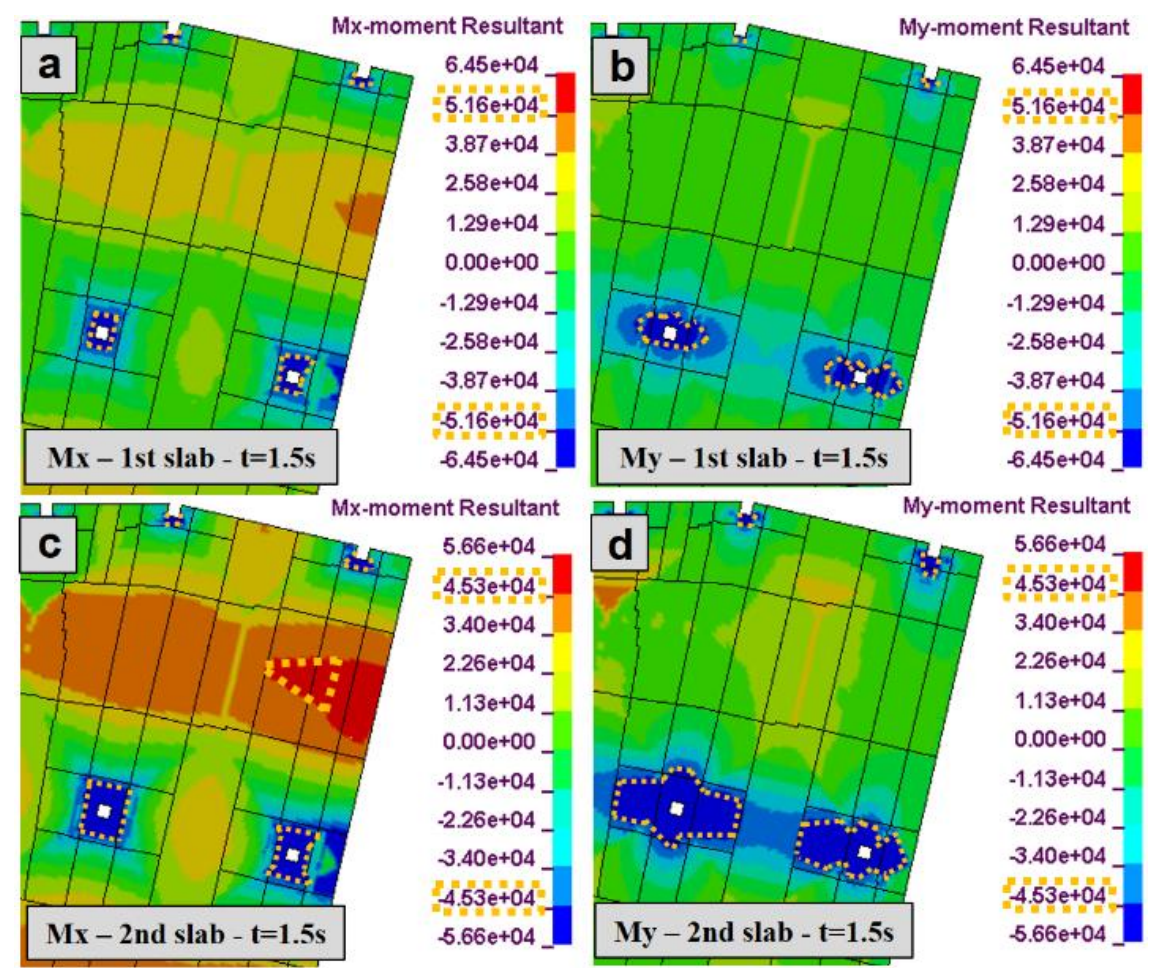

Fig. 17. Bending moments of first slab (a and b) and second slab (c and d) using load limiters (units in $\mathbf{N}$ ). 


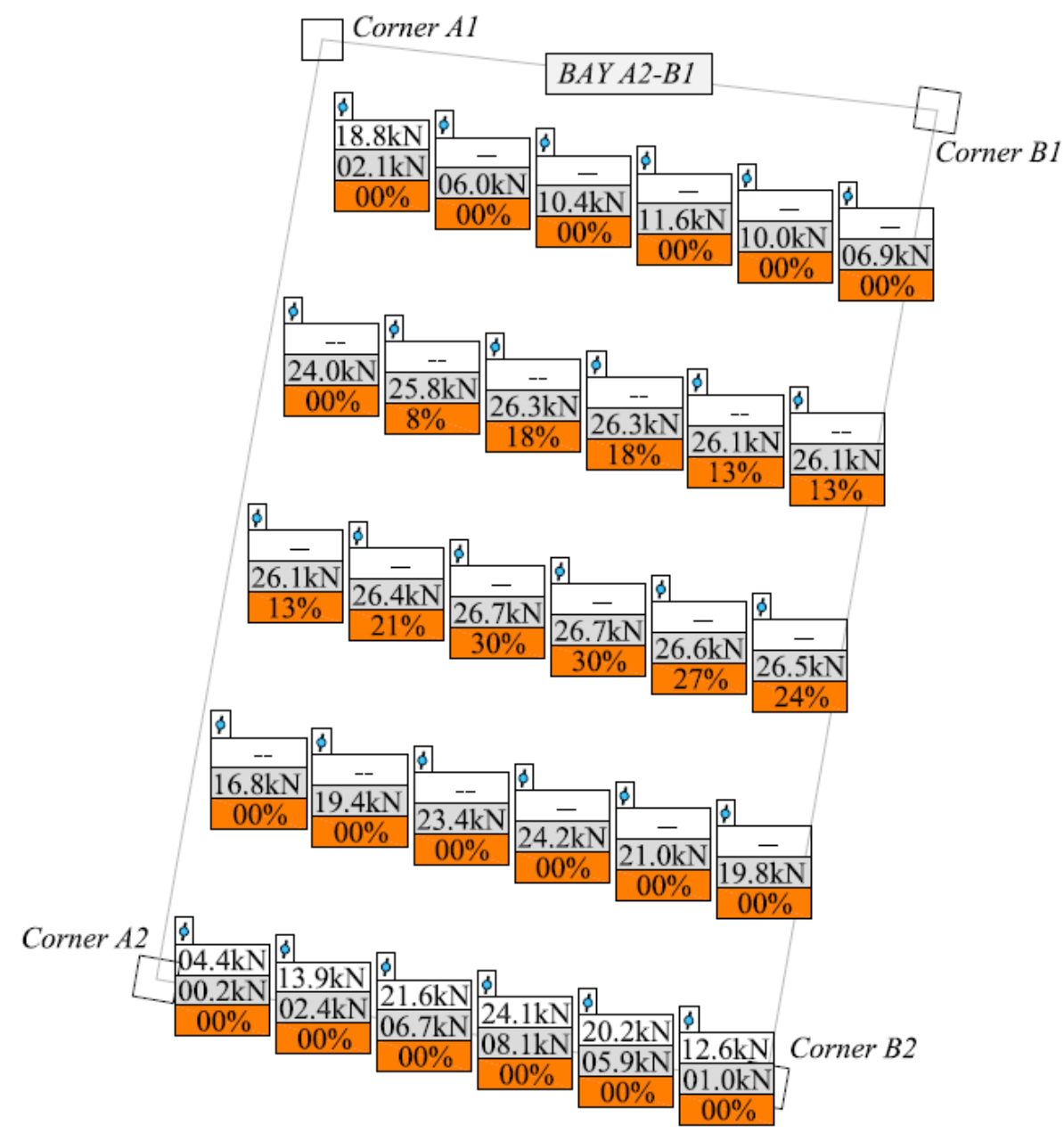

420 Fig. 18. Ground floor shore loads without LLs (white background -first row-) and with LLs (grey background -second row-), and percentage of use of the maximum LL plastic displacement (orange background -third row-).

\subsubsection{Discussion of raw and mitigated risks}

A summary of the slab loads and maximum residual displacement obtained in the analysis are shown in Table 1 for the cases without and with LLs in the two scenarios studied. These results are extracted and summarized from the dynamic analysis performed in previous sections and show

427 the improvement achieved using LLs in reducing damage in the slabs with early-age concrete (14

428 days and 7 days for the first and second slab respectively) after the accidental event. In terms of consequences, the structural analysis in this work showed that LLs reduced the consequence scale

430 from "significant/minor" to "minimal" using the IStrutE risk-assessment consequence scale [49]

431 ("significant" means no collapse of the floor slab but potential loss of some local structural 
433 considers only some visible damage requiring only some cosmetic repairs).

Table 1. Maximum displacement and loads on slabs for the different failure scenarios without and 435 with the use of LLs on shores.

\begin{tabular}{|c|c|cccc|cccc|}
\cline { 3 - 10 } \multicolumn{1}{c|}{} & \multicolumn{4}{c|}{$3^{\text {rd }}$ Scenario } & \multicolumn{4}{c|}{$4^{\text {th }}$ Scenario } \\
\cline { 2 - 10 } \multicolumn{1}{c|}{} & \multicolumn{2}{c|}{$\begin{array}{c}\text { Load } \\
{\left[\mathrm{kN} / \mathrm{m}^{2}\right]}\end{array}$} & \multicolumn{2}{c|}{$\begin{array}{c}\text { Max. Displacement } \\
{[\mathrm{mm}]}\end{array}$} & \multicolumn{2}{c|}{$\begin{array}{c}\text { Load } \\
{\left[\mathrm{kN} / \mathrm{m}^{2}\right]}\end{array}$} & \multicolumn{2}{c|}{$\begin{array}{c}\text { Max. Displacement } \\
{[\mathrm{mm}]}\end{array}$} \\
\cline { 2 - 10 } & $\begin{array}{c}\mathrm{t} \\
\text { [days }]\end{array}$ & $\begin{array}{c}\text { Without } \\
\text { LL }\end{array}$ & $\begin{array}{c}\text { With } \\
\text { LL }\end{array}$ & $\begin{array}{c}\text { Without } \\
\text { LL }\end{array}$ & $\begin{array}{c}\text { With } \\
\text { LL }\end{array}$ & $\begin{array}{c}\text { Without } \\
\text { LL }\end{array}$ & $\begin{array}{c}\text { With } \\
\text { LL }\end{array}$ & $\begin{array}{c}\text { Without } \\
\text { LL }\end{array}$ & $\begin{array}{c}\text { With } \\
\text { LL }\end{array}$ \\
\hline $\begin{array}{c}1 \text { st } \\
\text { Floor } \\
\text { 2nd } \\
\text { Floor }\end{array}$ & 14 & 8.0 & 6.2 & 13.7 & 6.9 & 10.0 & 6.3 & 18.6 & 5.5 \\
\hline
\end{tabular}
obtained from the structural analysis and the probability of occurrence for the "unlikely" class which corresponds to a $10 \%$ probability of occurrence during the design life [49]. Probability class "likely" corresponds to $50 \%$ and "rare" is for $2 \%$ probability. The probability of occurrence of the $4^{\text {th }}$ failure scenario (between $6 \%$ to $26 \%$ ) can be slightly higher than for the $3^{\text {rd }}$ failure scenario (between 3\% to $18 \%$ ) depending on the causes as discussed in more detail in $[9,17]$. The adopted probability class is consistent with the one used in the example building in the IStructE manual for the hazard identified as failure of temporary works during construction [49]. The black line shown in Fig. 19 shows a typical tolerable risk threshold used in the IStructE manual [49] which is roughly consistent with Annex B in EN 1991-1-7:2006 [50]. Fig. 19 shows that the raw risk of failure of the shoring system is very close to the threshold which is undesirable. The situation can worsen depending on the role of the slab where the damage takes place affecting the severity of the consequence from "minor/significant" to "significant" in Fig. 19. For example, as

450 reported in [49], for transfer slabs in ground floors damage on the member can have significant 451 implications.

452 Fig. 19 shows that introducing the LLs on the shores will shift the risk (mitigated risk) into the tolerable risk represented by the green boxes in the risk matrix. A cost-benefit analysis is 
generally recommended to finalise the implementation of the risk mitigating measures, followed

455 by the review of the residual risks and carry out a check on the risk assessment [49].

\begin{tabular}{|c|l|l|l|l|l|l|l|}
\hline $\begin{array}{c}\text { Cons. } \rightarrow \\
\downarrow \text { Prob. }\end{array}$ & Minimal & Minor & Signif. & Serious & Subst. & Severe & Catast. \\
\hline Freq. & & & & & & & \\
\hline Likely & & & & & & & \\
\hline Unlikely & $3^{\text {rd }} ; 4^{\text {th }}$ & & $3^{\text {rd }} ; 4^{\text {th }}$ & & & & \\
\hline Rare & & & & & & & \\
\hline Improb. & & & & & & & \\
\hline Negl. & & & & & & & \\
\hline
\end{tabular}

\begin{tabular}{|lllll}
$\mathrm{x}$ & Raw risk $\mathrm{x}$ & Mitigated risk & Typical tolerable risk threshold
\end{tabular}

Fig. 19. Analysis of raw and mitigated risk after introducing LLs for the $3^{\text {rd }}$ and $4^{\text {th }}$ failure scenarios; risk matrix based on [49] (green: tolerable risk; red: intolerable risk).

\section{Conclusions}

The use of structural fuses as load limiters on shores during construction is promising in terms of improving the shoring system design and reducing costs as shown in [35]. This paper analyses the consequences and advantages of using load limiters during building construction under accidental events. The present study considers possible failure scenarios, some of them resulting into the progressive collapse of the shoring system and some structural damage in the permanent structure (concrete slabs). From the study, the following conclusions can be drawn:

- The results show that installing LLs on the shores increased safety during the construction phase, maintaining the integrity of the temporary shoring structure, preventing excessive loads and displacements being transferred into the permanent RC structure and avoiding residual damage. Using LLs on shores prevented the sudden local failure of the shoring system, which can cause progressive collapse of the structure as observed in some accidents.

- Design standards [12] are starting to consider progressive collapse of temporary shoring with the idea that local damage can trigger a more serious progressive 
collapse. In this context, this work shows that LLs is a promising solution to prevent progressive collapse and mitigate residual damage (e.g. cracking and short/long term deflections) after accidental events. This is relevant towards avoiding costly structural repairs and improve the long-term performance of the structure.

\section{Acknowledgements}

The authors would like to express their gratitude to the Spanish Ministry of Education,

494 Culture and Sport for funding received under: a) the FPU Program [FPU13/02466] and 495 complementary funding received for a stay at the University of Surrey (UK), and b) the Mobility 496 Program (Salvador de Madariaga 2017) of the Promotion of Talent and Employability within the 497 state's Research \& Innovation Program 2013-2016 [PRX17/00302]. The authors would also like 498 to thank the Generalitat Valenciana for funding received [GV/2015/063], Dr. P. Olmati, who developed the preliminary FE model of the structure at the operational stage as part of a project sponsored by the EPSRC Impact Acceleration Account held by the University of Surrey [Grant 
502 and Dr. J. Asensi for providing the photograph included in Fig. 1.

\section{References}

504 [1] Terwel K, Mud M, Frijters A. Structural safety during construction. IABSE Madrid Symp Eng Progress, Nat People 2014;102:1071-8. doi:10.2749/222137814814067248.

[2] Hadipriono FC, Wang H-K. Causes of falsework collapses during construction. Struct Saf 1987;4:179-95. doi:10.1016/0167-4730(87)90012-9.

[3] Eldukair ZA, Ayyub BM. Analysis of Recent U.S. Structural and Construction Failures. J Perform Constr Facil 1991;5:57-73. doi:10.1061/(ASCE)0887-3828(1991)5:1(57).

[4] Epaarachchi DC, Stewart MG, Rosowsky D V. Structural Reliability of Multistory Buildings during Construction. J Struct Eng 2002;128:205-13. doi:10.1061/(ASCE)07339445(2002)128:2(205).

513 [5] Gross JG. Building Structural Failures-Their Cause and Prevention. J Prof Issues Eng 1986;112:236-48. doi:10.1061/(ASCE)1052-3928(1986)112:4(236).

[6] Fang D, Geng C, Zhang C, Zhu H, Liu X. Reliability of reinforced concrete buildings during construction. Tsinghua Sci Technol 2004;9:710-6.

[7] Carper KL. Structural Failures During Construction. J Perform Constr Facil 1987;1:13244. doi:10.1061/(ASCE)0887-3828(1987)1:3(132).

[8] Kaminetzy D V., Stivaros PC. Early-Age Concrete: Construction Loads, Behavior, and

[10] Soane A. Learning from failures. Des. Conf. Risk Manag., London: IStructE - Confidential Reporting on Structural Safety (CROSS); 2018.

[11] Falsework: Interim report of the Advisory Committee on Falsework - HMSO. 1974.

[12] BS 5975. Code of practice for temporary works procedures and the permissible stress design of falsework 2011.

[13] DoD. Department of Defense. Design of buildings to resist progressive collapse (UFC 4023-03); 2009.

[14] GSA. General Services Administration. Progressive collapse analysis and design guidelines for new federal office buildings and major organization projects; 2013.

[15] EN 1992-1-1. Eurocode 2: Design of concrete structures - Part 1-1: General rules and rules for buildings; 2004.

536 [16] CS: Concrete Society. Formwork. A guide to good practice, 3rd edition. 2013.

537 [17] Buitrago M, Sagaseta J, Adam JM. Effects of sudden failure of shoring elements in concrete building structures under construction. Eng Struct 2018;172:508-22. doi:10.1016/j.engstruct.2018.06.052. puntales telescópicos de obra. Patent number ES2636833, 2017. 
[19] Adam JM, Buitrago M, Moragues JJ, Calderón PA. Limitations of Grundy \& Kabaila's simplified method and its repercussion on the safety and serviceability of successively shored building structures. J Perform Constr Facil 2017;31:1-10. doi:10.1061/(ASCE)CF.1943-5509.0001038.

[20] Grundy P, Kabaila A. Construction Loads on Slabs with Shored Formwork in Multistory Buildings. J Proc 1963;60:1729-38.

[21] Mosallam KH, Chen W-F. Design considerations for formwork in multistorey concrete buildings. Constr Build Mater 1992;6:23-30. doi:10.1016/0950-0618(92)90024-S.

[22] Duan MZ, Chen WF. Improved simplified method for slab and shore load analysis during construction. Proj Rep CE-STR-95-21 1995.

[23] Fang DP, Geng CD, Zhu HY, Liu X La. Floor load distribution in reinforced concrete buildings during construction. ACI Struct J 2001;98:149-56.

[24] Alvarado YA, Calderón PA, Gasch I, Adam JM. A numerical study into the evolution of loads on shores and slabs during construction of multistorey buildings. Comparison of partial striking with other techniques. Eng Struct 2010;32:3093-102. doi:10.1016/j.engstruct.2010.05.028.

[25] Simavorian D, De Brito J, Castro L, Azenha M. Analysis of the effect of shoring on the behaviour of reinforced concrete slabs. Constr Build Mater 2017;143:473-89. doi:10.1016/j.conbuildmat.2017.03.096.

[26] Ruiz-Pinilla JG, Adam JM, Pérez-Cárcel R, Yuste J, Moragues JJ. Learning from RC building structures damaged by the earthquake in Lorca, Spain, in 2011. Eng Fail Anal 2016;68:76-86. doi:10.1016/j.engfailanal.2016.05.013.

[27] Del Coz Díaz JJ, Martínez-Luengas AL, Adam JM, Martín Rodríguez A. Non-linear hygrothermal failure analysis of an external clay brick wall by FEM - A case study. Constr Build Mater 2011;25:4454-64. doi:10.1016/j.conbuildmat.2010.12.039.

[28] Delatte N. Failure literacy in structural engineering. Eng Struct 2010;32:1952-4. doi:10.1016/J.ENGSTRUCT.2009.12.015.

[29] Feld J. Building failures: floor support shoring in multi-storey construction. Build Res Pract 1974;2:151-5. doi:10.1080/09613217408550309.

[30] Khudeira S. Building Collapse during Construction. Pract Period Struct Des Constr 2010;15:99-100. doi:10.1061/(ASCE)SC.1943-5576.0000058.

[31] Alvarado YA. Estudio experimental y numérico de la construcción de forjados hormigonados in situ mediante procesos de cimbrado, clareado y descimbrado de plantas consecutivas. PhD Thesis - Universitat Politècnica de València. [In Spanish], 2009.

[32] Adam JM, Parisi F, Sagaseta J, Lu X. Research and practice on progressive collapse and robustness of building structures in the 21st century. Eng Struct 2018;173:122-49. doi:10.1016/j.engstruct.2018.06.082.

[33] Pallet PF, Burrow MPN, Clark LA, Ward RT. Investigation into aspects of falsework. Contract Research Report 394. 2001.

[34] Whittle R. Failures in concrete structures: case studies in reinforced and prestressed concrete. CRC Press/Talylor and Francis; 2013.

[35] Buitrago M, Alvarado YA, Adam JM, Calderón PA, Gasch I, Moragues JJ. Improving construction processes of concrete building structures using load limiters on shores. Eng Struct 2015;100:104-15. doi:10.1016/j.engstruct.2015.06.007.

Buitrago M, Adam JM, Calderón PA, Moragues JJ. Load limiters on shores: Design and 
experimental research. Eng Struct 2018;173:1029-38.

doi:10.1016/j.engstruct.2018.07.063.

[37] CS: Concrete Society. Guide to the design and construction of reinforced concrete flat slabs. Technical report no 64; 2007.

591

592

593

[38] Olmati P, Sagaseta J, Cormie D, Jones AEK. Simplified reliability analysis of punching in reinforced concrete flat slab buildings under accidental actions. Eng Struct 2017;130:83-98. doi:10.1016/j.engstruct.2016.09.061.

[39] Alsina Formwork Solutions 2019. http://www.alsina.com/.

[40] LSTC. LS-DYNA theory manual 2012.

596

597

[41] EN 1991-1-6. Eurocode 1: Actions on structures - Part 1-6: General actions - Actions during execution; 2005.

598 [42] EN 1990. Eurocode: Basis of structural design; 2002.

599

[43] Sagaseta J, Olmati P, Micallef K, Cormie D. Punching shear failure in blast-loaded RC

600

601

602

603

604

605

606

607

608

609

610

611

612

613

614

615

616

617

618

619

620

[44] Pham AT, Tan KH, Yu J. Numerical investigations on static and dynamic responses of reinforced concrete sub-assemblages under progressive collapse. Eng Struct 2017;149:220. doi:10.1016/j.engstruct.2016.07.042.

[45] Ren P, Li Y, Lu X, Guan H, Zhou Y. Experimental investigation of progressive collapse resistance of one-way reinforced concrete beam-slab substructures under a middlecolumn-removal scenario. Eng Struct 2016;118:28-40. doi:10.1016/j.engstruct.2016.03.051.

[46] Brunesi E, Nascimbene R, Parisi F, Augenti N. Progressive collapse fragility of reinforced concrete framed structures through incremental dynamic analysis. Eng Struct 2015;104:65-79. doi:10.1016/j.engstruct.2015.09.024.

[47] Lim NS, Tan KH, Lee CK. Experimental studies of 3D RC substructures under exterior and corner column removal scenarios. Eng Struct 2017;150:409-27. doi:10.1016/j.engstruct.2017.07.041.

[48] Yu J, Luo L, Li Y. Numerical study of progressive collapse resistance of RC beam-slab substructures under perimeter column removal scenarios. Eng Struct 2018;159:14-27. doi:10.1016/j.engstruct.2017.12.038.

[49] Institution of Structural Engineers (IStructE). Manual for the systematic risk assessment of high-risk structures against disproportionate collapse. London: IStructE; 2013.

[50] EN 1991-1-7. Eurocode 1: Actions on structures - Part 1-7: General actions - Accidental actions; 2006.

621

622

623 
1. Shore buckling during the construction of a building structure.

2. Sketch of the shoring system and detail of a shore with load limiter.

3. LL conceptual behaviour before and after reaching the limit load.

4. a) Load limiter after reaching the maximum plastic displacement (slot height), and b) simplified LL on shore behaviour adopted for macro-scale models.

5. Building geometry and the shoring system considered.

6. FE model (a) and defined scenarios of sudden failure of ground floor shores (b).

7. Load limiter-shore behaviour using: (a) load limiters of $40 \mathrm{kN}$ and shores of $47.7 \mathrm{kN}$ strength for the third failure scenario, and (b) load limiters of $25 \mathrm{kN}$ and shores of $30.6 \mathrm{kN}$ strength for the incorrect selection of shores scenario.

8. Progressive collapse of the shoring system in the $3^{\text {rd }}$ failure scenario without LLs.

9. Displacements and structure/shoring system: (a) before the accidental event, (b and c) after the sudden event, without (b) and with (c) load limiters (LL) on shores (units in $\mathrm{mm})$.

10. Time history results of slabs and shoring for the 3rd failure scenario without LL (a, c, e, g) and with LL (b, d, f, h): a) and b) load of a single shore of level 1 and 2 for the most loaded shore under slab $1 ; \mathrm{c}$ ) and d) displacement of first and second floor for the bay under study and the adjacent bay $(\mathrm{AB})$ for the position of the most loaded shore under slab 1; e) and f) slab and shoring system loads for the first and second floor and the 1st and 2nd level respectively; and g) and h) load-displacement of 1st and 2nd slabs (displacement at the position of the most loaded shore of the ground floor).

11. Bending moments of first slab (a, b and c) and second slab (d, e and f) before (a and d) and after (b, c, e and f) the accidental event without (b and e) and with (c and f) load limiters (LL) for the $3^{\text {rd }}$ failure scenario (units in N).

12. Ground floor shore loads without LLs (white background-first row-) and with LLs (grey background -second row-), and percentage of use of the maximum plastic displacement of LLs (orange background -third row-).

13. Progressive collapse of the shoring system in the $4^{\text {th }}$ failure scenario without LLs.

14. Displacements and structure/shoring system after the accidental event $(t=1.5 \mathrm{~s})$ for the $4^{\text {th }}$ failure scenario: (a) without LLs and (b) with LLs (units in $\mathrm{mm}$ ).

15. Time history results of slabs and shoring for the 4th failure scenario without LL (a, c, e, g) and with LL (b, d, f, h): a) and b) load of a single shore of level 1 and level 2 for the most loaded shore under slab 1; c) and d) displacement of first and second floor for the bay under study and the adjacent bay $(\mathrm{AB})$ in the position of the most loaded shore under slab 1; e) and f) slab and shoring system loads for the first and second floor and the 1st and 2nd level respectively; and g) and h) load-displacement of 1st and 2nd slabs (displacement at the position of the most loaded shore of the ground floor). 


\section{List of Tables:}

692 1. Maximum displacement and loads on slabs for the different failure scenarios without and

16. Bending moments of first slab (a and b) and second slab (c and d) after the accidental event for the $4^{\text {th }}$ failure scenario, without load limiters on shores (units in $\mathrm{N}$ ).

17. Bending moments of first slab (a and b) and second slab (c and d) using load limiters (units in $\mathrm{N}$ ).

18. Ground floor shore loads without LLs (white background -first row-) and with LLs (grey background -second row-), and percentage of use of the maximum LL plastic displacement (orange background -third row-).

19. Analysis of raw and mitigated risk after introducing LLs for the $3^{\text {rd }}$ and $4^{\text {th }}$ failure scenarios; risk matrix based on [49] (green: tolerable risk; red: intolerable risk).

694 